JEFF FUHRER

Federal Reserve Bank of Boston

GIOVANNI P. OLIVEI

Federal Reserve Bank of Boston
ERIC S. ROSENGREN

Federal Reserve Bank of Boston

GEOFFREY M.B. TOOTELL

Federal Reserve Bank of Boston

\title{
Should the Federal Reserve Regularly Evaluate Its Monetary Policy Framework?
}

\begin{abstract}
Would a more open and regular evaluation of the monetary policy framework improve policy in the United States? Even when considering a relatively short time frame spanning the 1960s to the present, it is possible to point to many significant changes to the framework. Some of the changes were precipitated by acute economic conditions; others were considered and implemented only gradually, as a response to long-standing problems with the framework. But to date, the process for evaluating and changing frameworks has not always been transparent, and changes have not always been timely. Could a more formal, and open, review process improve how well we adhere to our current framework? Could transitions to a new framework be made more effectively? We conclude that such a review might indeed be beneficial, and outline one possible review process.
\end{abstract}

- ron rom the inception of central banking, policymakers have adjusted their monetary policy frameworks in light of the economics profession's evolving understanding of monetary economics, changes in the structure of the economy, and the obvious failures of previously used regimes. The lineaments of the current framework for the Federal Reserve are outlined in the most recent January "Statement on Longer-Run Goals and Monetary

Conflict of Interest Disclosure: The authors are officers and employees of the Federal Reserve Bank of Boston. Beyond this shared affiliation, the authors did not receive financial support from any firm or person for this paper or from any firm or person with a financial or political interest in this paper, and they are currently not officers, directors, or board members of any organization with an interest in this paper. No outside party had the right to review this paper before circulation. The views expressed in this paper are those of the authors, and do not necessarily reflect those of the Board of Governors of the Federal Reserve System or the Federal Open Market Committee. 
Policy Strategy." In addition to specifying the 2 percent numerical inflation objective and the specific price index that the Federal Open Market Committee (FOMC) will target, the document emphasizes the symmetry of the inflation goal and the role that communication plays in anchoring longerterm inflation expectations. The document also articulates the symmetry of the FOMC's loss function with respect to deviations of inflation from target and employment from the FOMC's assessment of its long-run level, noting also that in circumstances when these dual objectives are in conflict, the FOMC "follows a balanced approach in promoting them." Finally, and particularly important for this paper, the document notes the FOMC's intent "to reaffirm these principles and to make adjustments as appropriate in its annual organizational meeting each January." Exploring whether a formal process might help reduce any obstacles to making these adjustments more effective is the aim of this paper.

How often have such adjustments been required? As this paper illustrates, changes have occurred quite frequently. Almost none of the elements in the current framework existed when the Federal Reserve System was founded in 1913, and most of them have been codified only very recently. These changes, though sometimes significant, did not require enabling legislation, but simply the FOMC's agreement. In short, the history of the United States' monetary policy framework is one of nearly continuous changes, both minute and momentous. Broadly, over the past 100 years, the monetary framework has progressed from the Gold Standard, to the Bretton Woods monetary system, to the Treasury Accord, to goal-andinstrument independence, to just instrument independence, to the formal adoption of an explicit numerical objective for price stability, to the use of balance sheet policy to augment conventional policy during the Great Recession, to the 2012 adoption of an explicit framework document that evolved to outline a symmetric and equally weighted emphasis on both aspects of the Fed's congressionally given dual mandate.

Thus, in reality, the question is not whether the framework can or should change, but what are the appropriate triggers for such changes and what process might best aid the central bank in considering how to change it. As a point of comparison, on February 26, 1991, the Bank of Canada announced an inflation-control target framework, which was extended in 1993, along with a pledge to review it again in 1998. In 2001, the Bank of Canada established a five-year cycle to ensure that its monetary policy framework would remain effective as the economy, and the central bank's understanding of it, evolve. Every five years, the Bank of Canada conducts a formal review of the goals of monetary policy as well as alternative 
approaches to attaining these goals, considerations such as lowering or raising the 2 percent inflation target, whether to target the price level, and the role of financial stability. The process of reevaluation includes staff research on key topics in the years leading up to the decision date, and invites feedback from the public, the government, and academics (see Murray 2018).

Would a more comprehensive and regular evaluation of the framework improve monetary policy in the United States? To answer this question, one needs to understand why framework changes have occurred; how and how quickly the shortcomings of earlier frameworks were recognized, and thus whether one can reasonably expect to improve the way in which framework changes occur; and whether a regular review process could be part of this improvement. It is important to recognize that framework reassessment is not entirely episodic and event-driven. Staff and principals within the Federal Reserve System are involved in a continuous reassessment of the framework. And there is also considerable interaction between the Fed, academics, other central banks, and other policy institutions, and this interaction provides some opportunity to consider emerging ideas about how to improve the conduct of policy.

However, U.S. monetary history-certainly including the Great Depression, and possibly the Great Inflation of the 1970s, the Great Recession, and the 2008-9 financial crisis of very recent history-might suggest that the existing combination of internal processes and external interactions does not always produce the optimal framework. Would more focused internal analysis at regular intervals be helpful? Would a more formal incorporation of external analysis from academics and others improve the Fed's performance at key junctures? This paper tentatively concludes that such a process may help the Fed more effectively make needed framework changes. Whether the source of any problems is Fed errors or the profession's understanding, a regular reevaluation process, both external and internal, may help to more efficiently change the framework when needed.

We wish to emphasize that the framework changes we have in mind are not ones that would require amendments to the existing legislation, which would obviously fall under the purview of Congress. Rather, they are largely technical changes meant to improve the conduct of monetary policy to better achieve the congressionally mandated goals.

The paper begins by defining, in section I, what is meant by a monetary policy framework. To anticipate, the definition necessarily entails "gray areas." In section II, we consider the history of changes in the monetary policy framework for the U.S. central bank in the modern era. 
From this review, we hope to get a sense of the frequency of changes, the motivation for changes, and a sense of which measures we might use to gauge the success or failure of the historical frameworks. Section III discusses a host of practical questions about the process for reevaluating the Fed's monetary policy framework. Section IV discusses whether the Fed might consider a change in the framework given the current circumstances, and section $\mathrm{V}$ concludes.

\section{How Do We Define a Monetary Policy Framework?}

Broadly, a monetary policy framework may be defined as the set of tools and processes by which the central bank attempts to define and attain its high-level economic goals. The central bank might be allowed to choose some components of this process, such as the precise inflation target and the transparency of the policy. But some elements of the framework are strongly influenced by other factors outside the central bank's control, such as the structure of the economy and the desires of the public. Given this definition of the framework, it follows that the changes in the framework in which we are most interested are those that significantly affect the central bank's ability to achieve its high-level goals on behalf of the public. More specifically, a monetary policy framework will include eight main elements.

The first element is the governance structure of the central bank. This paper largely abstracts from how the central bank fits into the country's governmental structure-for example, whether it is, statutorily, an instrument independent of the executive branch and the Treasury. Such considerations have been shown to importantly affect the efficacy of central bank actions, but we assume in this paper that the Fed, both legislatively and practically, has a high degree of independence. ${ }^{1}$ A related high-level concept is that of accountability: the responsibility delegated to the central bank by Congress to deliver acceptable economic outcomes to the country's citizens. Many efforts to improve transparency have been rooted in a desire to provide the public with explanations for why the Fed does what it does, an essential component of accountability.

The second element is a set of ultimate goals for the central bank. Today, we have a congressionally mandated set of goals - the so-called dual mandate, which comprises "stable prices" and "maximum employment"phrases that have been modified in common usage to "price stability" or

1. For issues pertaining to the Federal Reserve's governance, see, among others, Binder and Spindel (2016) and Conti-Brown (2016). 
"low and stable inflation" and "maximum sustainable employment." The goals have changed through time. When the Fed was founded in 1913, its goals focused primarily on stability of the banking system. The gold standard demanded fixing the dollar price of gold. Obviously, both sets of goals differed dramatically from the Fed's responsibilities in the current framework. In the long run, even the dual mandate might be altered. For example, recurring bouts of financial instability might prompt the Fed to be more explicit about the role of monetary policy in preventing and offsetting such disruptions. ${ }^{3}$

The third element is a loss function. An articulation of goals is not sufficient. Unless the framework entails a single, rigidly defined goal, it needs to include a loss function (or the equivalent) that describes how the central bank weights its (sometimes competing) goals. ${ }^{4}$ For example, the Fed needs to say whether it considers losses on either side of the target inflation or employment goals symmetrically; how it weights deviations from its inflation goal versus deviations from its employment goal; whether it chooses a point target for inflation or a band; whether it allows the operational inflation goal to move somewhat over time; over what horizon it intends to bring inflation back to its goal; and so on. As an institution accountable to the public, the Fed might also explain where the targets come from, and what determines their values. Such an explication would also help illuminate why the framework might change through time.

The fourth element is instruments. The instruments that the central bank has directly controlled in attempting to achieve its key goals have, over time, included the dollar price of gold, the volume of various monetary and reserve aggregates, the level of short-term interest rates, and the size and composition of its balance sheet. Multiple instruments can and have been part of the same framework; for example, during the financial crisis, the Fed used the federal funds rate until it fell to its effective lower bound, at which point it pursued balance sheet policies in an attempt to better achieve its mandated goals.

The fifth element is the central bank's operational targets. The operational "target" (or targets) that the central bank sets so that it can achieve its

2. Federal Reserve Act, as amended, Section 2A-12 USC 225a, as added by act of November 16, 1977 (91 Stat. 1387), and as amended by acts of October 27, 1978 (92 Stat. 1897), August 23, 1988 (102 Stat. 1375), and December 27, 2000 (114 Stat. 3028).

3. See Peek, Rosengren, and Tootell (2015).

4. In some cases, a model's explicit microeconomic foundations allow one to derive a model-consistent loss function (see Rotemberg and Woodford 1997; Woodford 2002), and could inform the central bank's choice of a specific loss function. 
primary goals sometimes completely overlap its ultimate goals. A central bank that is a pure inflation targeter can use inflation as both its ultimate and operational targets. However, a central bank with both inflation and output as its ultimate goals could choose to use, for example, nominal GDP as the operational target to achieve its goals. Targeting nominal GDP imposes specific weights on deviations of prices from the desired pricelevel path and deviations of real output from potential, the ultimate goals of monetary policy. ${ }^{5}$

The sixth element is transparency. Transparency is often an important part of the framework, especially when it is enhanced to improve the efficacy of policy actions. It is also an important element of the framework because it improves a central bank's accountability to the public. One goal of transparency is to make monetary policy more predictable. For example, the release of FOMC or staff forecasts, which signal future policy, and publishing alternative scenarios could (at least in theory) help the public to understand the current and expected setting of policy, which might lead to a more predictable and efficient transmission of policy actions into other asset prices. In fact, one motivation for revisiting the monetary policy regime every few years is to ensure that the regime is clear to the public. The costs of opacity can be high. For example, the profession has struggled with understanding the poor performance of the economy in the 1970s and early 1980s (and this paper is no exception), in part because of this lack of clarity about the framework. In the extreme, the Fed may want to set expectations with clear forward guidance. The ability of the central bank to affect expectations is a topic of active discussion, and much has been written about the wisdom of attempting it, as well as the efficacy of historical attempts (see, for example, King, Lu, and Pastén 2008).

The seventh element includes rules and discretion-the systematic component of monetary policy. Given a set of goals, an articulation of the loss function, a set of instruments, and perhaps an intermediate target, a central bank should generally aim to conduct monetary policy in a systematic, and thus predictable, fashion. As a consequence, even if transparency is minimal, one may be able to discern with some accuracy the policy rule implications of a framework. That rule will not capture all features of the framework - in particular, a simple rule would fail to capture asymmetries in the uncertainty about the outlook—but it can reflect, in a compact way,

5. The desire to use nominal GDP as an operational target might arise from equal weights on price and output deviations in the loss function, or from other practical considerations that suggest it would deliver desirable outcomes relative to other operational targets. 
many aspects of the framework. To the extent that a central bank's behavior can be well described by a policy rule, whether this rule is articulated by the bank or can be accurately inferred by the public from the bank's actions, policy predictability will be enhanced, and the transmission channel will be more effective. At the same time, under certain conditions, truly optimal policy may deviate noticeably from simple rules, and thus discretion may be an important component of the policy framework.

One important element of discretion is risk management. Most discussion to this point has abstracted from how the evaluation of and response to risk might fit into the monetary policy framework. This is not a trivial omission; indeed, then-Fed chairman Alan Greenspan $(2004,2005)$ often described the business of monetary policy as in large part an exercise in risk management. The evaluation of risk-or, more specifically, the consideration of asymmetry in the distribution of policy-relevant outcomes, along with the possibility of abnormally large tail risks- has clearly played a role in FOMC deliberations over the years. Most notably, financial stability risks have risen in prominence in the FOMC's discussions. Providing a precise analytical framework for the Fed's, or any other central bank's, systematic response to such risks is beyond the scope of this paper. But in attempting a definition of the monetary policy framework, the response to and management of risk is a nontrivial element.

Finally, the eighth element is the central bank's depiction of the economy - "the model." Broadly speaking, the model that the central bank uses to describe the economy's evolution and the interactions between policy and the real and financial economies can both constrain and influence the regime chosen by the central bank. ${ }^{6}$ In a committee such as the FOMC, different members can base their policy recommendations on different models while still sharing the same elements of the framework we have already outlined. Nevertheless, common features across models are crucial inputs to the policy process - the equilibrium real rate of interest, the natural rate of unemployment, and the slope of the Phillips curve. Postwar U.S. history appears to have experienced quite persistent and significant fluctuations in most if not all of these key parameters, as illustrated in section II below. Such changes in economic structure can also spur modifications to the monetary policy framework, although not all changes will require a shift in the framework. For example, when changes in economic

6. For a given economic structure or model, one can entertain any number of monetary policy frameworks that might work within it. In this sense, the model is not part of the framework, although it can clearly influence the choice and efficacy of frameworks. 
structure constrain the framework-such as when a drop in the equilibrium rate makes it more likely that the effective lower bound will bind - then a framework change may be needed.

In addition, the current instantiation of a central bank's economic model reflects current economic wisdom as accepted (and perhaps modified) by the central bank. One can take for granted, in present circumstances, the importance of explicit expectations; of macroeconomic behavior that is grounded to some extent in microeconomic behaviors; of the importance of accounting identities, budget constraints, and adding up constraints; and of the absence of a long-run trade-off between unemployment and inflation, given that most modern models reflect such concepts to varying degrees. But these have not always been features of the models used by central banks in the conduct of monetary policy, and several of them have changed the way banks think about conducting monetary policy, and thus about what are viewed as better and worse frameworks.

There is no widely agreed-upon definition of what constitutes a monetary policy framework, but the eight key elements described here should be useful as guideposts as we consider both the history of the U.S. monetary policy framework and its possible evolution. Again, it is important to recognize that though these elements appear as distinct components in the description above, in practice there will be both gray areas in the definitions and overlap among the components as they are used in any specific framework.

\section{A Review of Monetary Policy Frameworks since the 1960s}

We now provide our assessment of framework changes over time, using the previous section's taxonomy. Many of the changes we identify are discussed in Allan Meltzer's history of the Federal Reserve (2002, 2010, 2014) and by Christina Romer and David Romer (2002, 2013). These works are based on a thorough reading and interpretation of the minutes of the FOMC's meetings. Here, we complement some empirical evidence with a word count of specific phrases used at FOMC meetings that may indicate a change in focus on key elements of the policy regimes at the time. When a given framework is operative, one would expect certain words related to this framework to arise more frequently. Our analysis is also organized around specific elements of the framework. As such, it is not necessarily exhaustive, but it is meant to highlight the fundamental issues and provide explanations for the reasons and processes that led to or hindered changes in the monetary policy framework. 
As Fed insiders, we also wish to emphasize that the framework is to some extent always under discussion and debate. The staffs of the Federal Reserve Board and the regional Fed banks are constantly working on memos and papers that examine possible changes to the framework. Another element of the work conducted at the Board and the regional banks concerns potential technical changes in key parameters of the economy. Such work is ongoing in the system and might need less coverage at a regularly scheduled public meeting, such as the one under consideration here. The deeper issues that correspond to the framework debates may be more appropriate for such gatherings.

It is useful to frame the discussion first in terms of realized outcomes and the policy frameworks in which they occurred. Figure 1 presents our version of the frameworks that have existed since the 1960s. The regimes are drawn in figure 1 with very broad brushstrokes. Still, we attempt to show some of the finer strands of the tapestry of monetary policy that run throughout the past 60 years, such as independence and transparency. It is important to note that, for the most part, lessons were not forgotten over this time period, so in many ways the regime changes are really an accumulation of knowledge. The regime names attempt to emphasize the added pieces in the puzzle acquired over a given period.

The realized outcomes are also presented in figure 1 by means of a quadratic loss function that weights inflation and unemployment equally. These losses could capture the costs of using the wrong framework, along with adverse shocks not related to monetary policy. Inflation and unemployment are taken as deviations from an estimate of the inflation target (when the target was not explicit), and the estimate by the Congressional Budget Office (CBO) of the natural rate of unemployment, respectively. ${ }^{7}$ The largest losses appear in the second half of the 1960s, the 1970s and early 1980s, and with the recent Great Recession. ${ }^{8}$ The "Volcker disinflation" occurred after about 15 years of large welfare losses, and required a very costly recession to alter the course of inflation and inflation expectations. Although not all the large economic losses represented in the figure were the direct consequence of FOMC policies, it is relevant to ask whether a

7. We measure inflation with the latest vintage of the Q4/Q4 change in the core personal consumption expenditures deflator. Details about the estimation of the time-varying inflation target are provided in section II of the paper.

8. A time-varying target for inflation reduces the loss during the 1970s and early 1980s, but the qualitative results in the figure continue to hold even with an inflation target fixed at 2 percent. 
Figure 1. Loss Functions and Regimes, 1960:Q1-2018:Q1

Percent

Bretton

Woods/

Regime

post accord without targets
Targets with no road map: opportunistic disinflation
Credibility and transparency

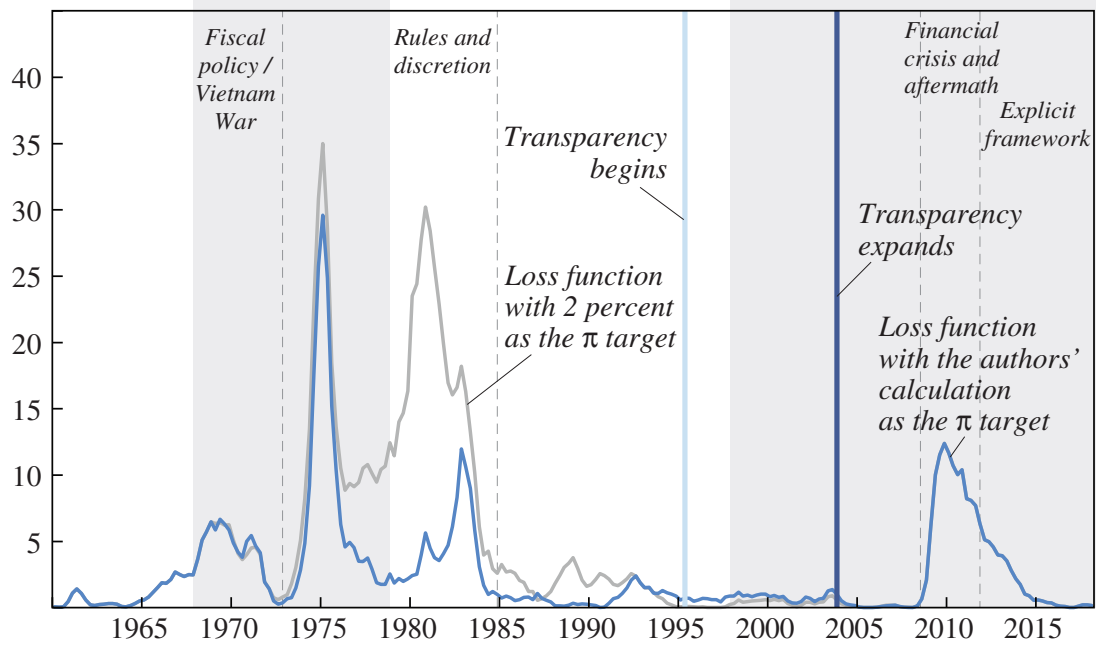

Sources: Authors' calculations; Bureau of Economic Analysis; Bureau of Labor Statistics; Congressional Budget Office; Federal Reserve Board.

more systematic evaluation of the framework might reduce such losses, whether they resulted from delaying actions, adherence to a broken framework, misperception of key aspects of economic structure, or discretionary deviations from an otherwise well-functioning framework.

\section{II.A. Regimes without and with Explicit Targets}

With the demise of the Bretton Woods monetary system, and the demands of financing the Vietnam War, the Fed's mandate became less clear. To examine this issue, this subsection explores the Fed's inflation model. In so doing, we also comment on recent developments that have a bearing on the policy framework. The Fed grapples constantly with its model of inflation. Here, we infer the evolution of the FOMC's views about inflation from the inflation predictions made by the staff of the Federal Reserve Board and published in the Greenbook/Tealbook (GB/TB). This analysis is related to and extends the work of Romer and Romer (2002). The GB/TB inflation 
forecast for a particular quarter is modeled as a function of lagged inflation and the unemployment rate:

$$
E_{t} \pi_{t+i}=\beta_{0, t}+\beta_{1, t} E_{t} \pi_{t+i-1}^{4}+\beta_{2, t} E_{t} u_{t+i-1}+v_{i, t}, \quad i=1,2,3
$$

where $\pi_{t+i}$ denotes the annualized rate of inflation in quarter $t+i, \pi_{t+i-1}^{4}$ is the average rate of inflation prevailing over the four quarters from $t+i-1$ to $t+i-4$, and $u_{t+i-1}$ is the level of the unemployment rate at $t+i-1$. The operator $E_{t}$ denotes a forecast made in quarter $t$. We consider forecasts of inflation one, two, and three quarters out, as indexed by $i$. At each of the three forecasts of quarterly inflation horizons, the relationship is augmented by an error term, $v_{i, t}$, which captures other factors that influence the inflation forecast besides past inflation and the unemployment rate. An important feature of equation 1 is time variation in the $\beta$ coefficients, which is assumed to occur as a random walk.

Details about the data and estimation are provided in the appendix to this paper. Figure 2 reports the unsmoothed, time-varying estimates of the coefficients over the period 1966:Q4 to 2017:Q4. ${ }^{9}$ It is apparent that the weight given to lagged inflation, as measured by $\beta_{1, t}$, was low in the late 1960s and started to rise noticeably in the early 1970s. The first few estimates in the sample need to be interpreted with caution, because the available forecasts in the GB/TB often did not extend out four quarters. Initial conditions also matter, but it can be shown that the qualitative result of an increase in the importance of lagged inflation in the 1970s relative to the late 1960s is robust. This strand of the framework has recently regained importance, as there has been a noticeable decline in the weight placed on lagged inflation. As concerns the assessment of the short-run trade-off between inflation and unemployment, $\beta_{2, t}$ in equation 1 , the estimates are again noisy at the beginning of the sample, but views about the trade-off appear to have changed in the 1970s and 1980s. More recently, there has been a gradual but steady decline in the estimated impact of economic slack on inflation. The intercept term, $\beta_{0, t}$ also exhibits noticeable variation, and we comment on these fluctuations below.

In all, though admittedly simple, this exercise points to changes in the inflation model. Some of these changes have had a significant impact on

9. Given that the staff's forecasts are made public with a five-year lag, for the period from 2013 to the present, our analysis uses the FOMC's economic projections. The appendix provides details on how the forecasts from the "Summary of Economic Projections" are used in the analysis. 
Figure 2. Unsmoothed Estimated Coefficients for Equation 1, 1966:Q4-2017:Q4

Filtered state $\beta_{0}$ estimate

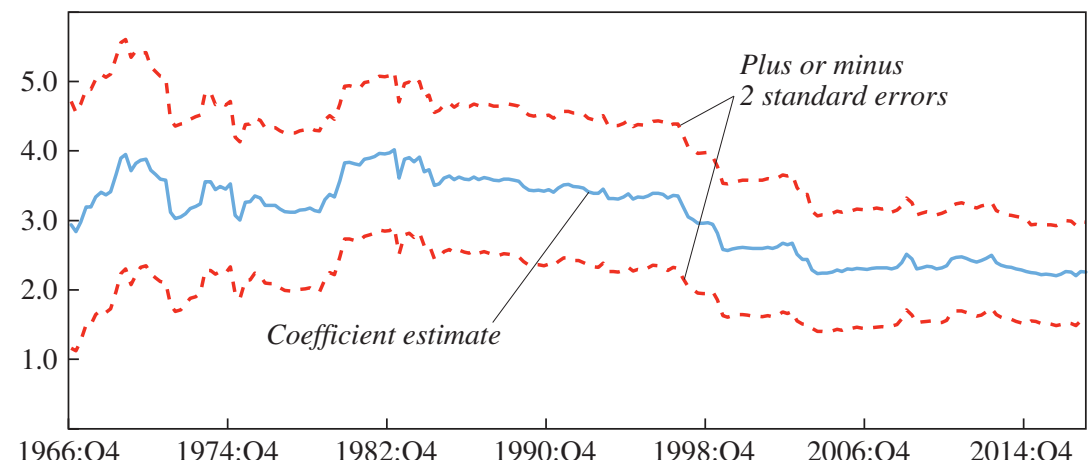

Filtered state $\beta_{1}$ estimate

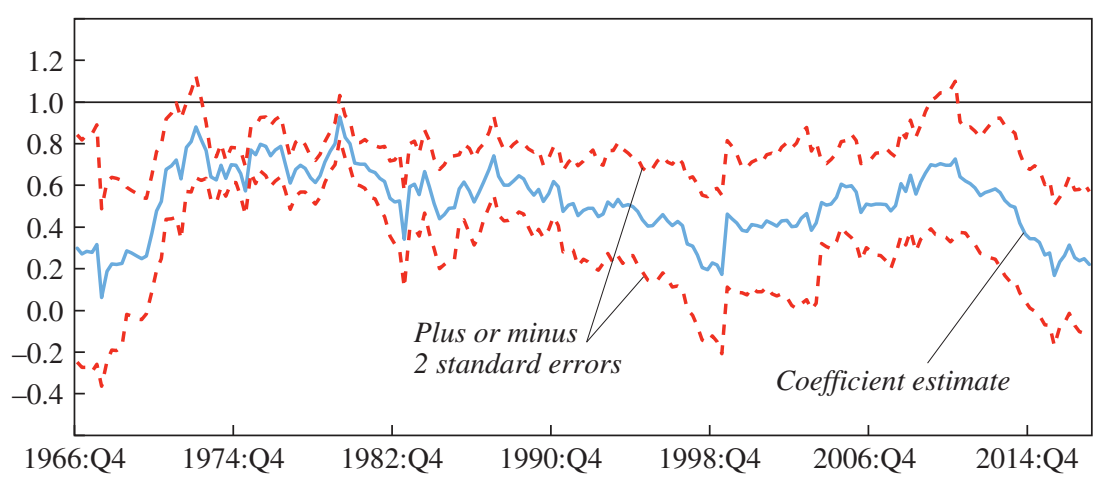

Filtered state $\beta_{2}$ estimate

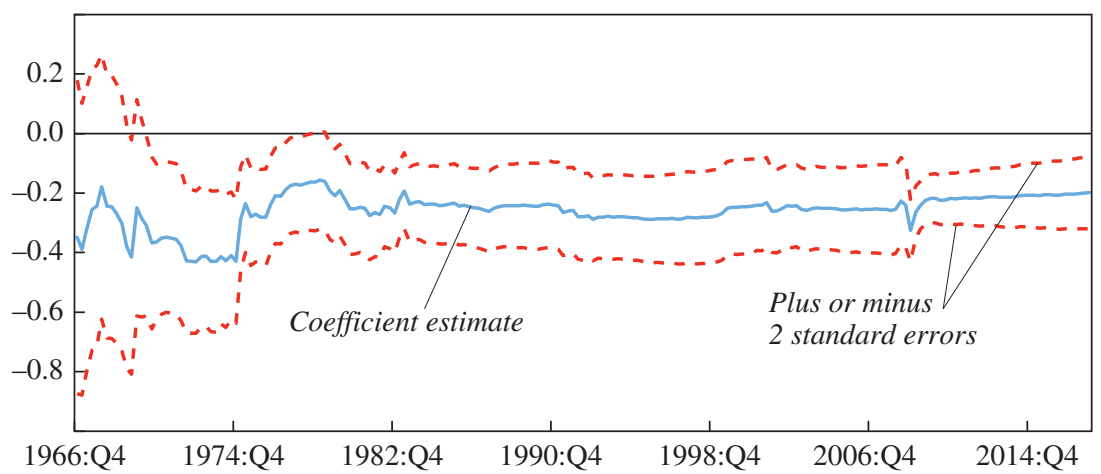

Sources: Authors' calculations; Federal Reserve Board. 
Figure 3. Mentions of Inflation as a Problem, 1966-79a

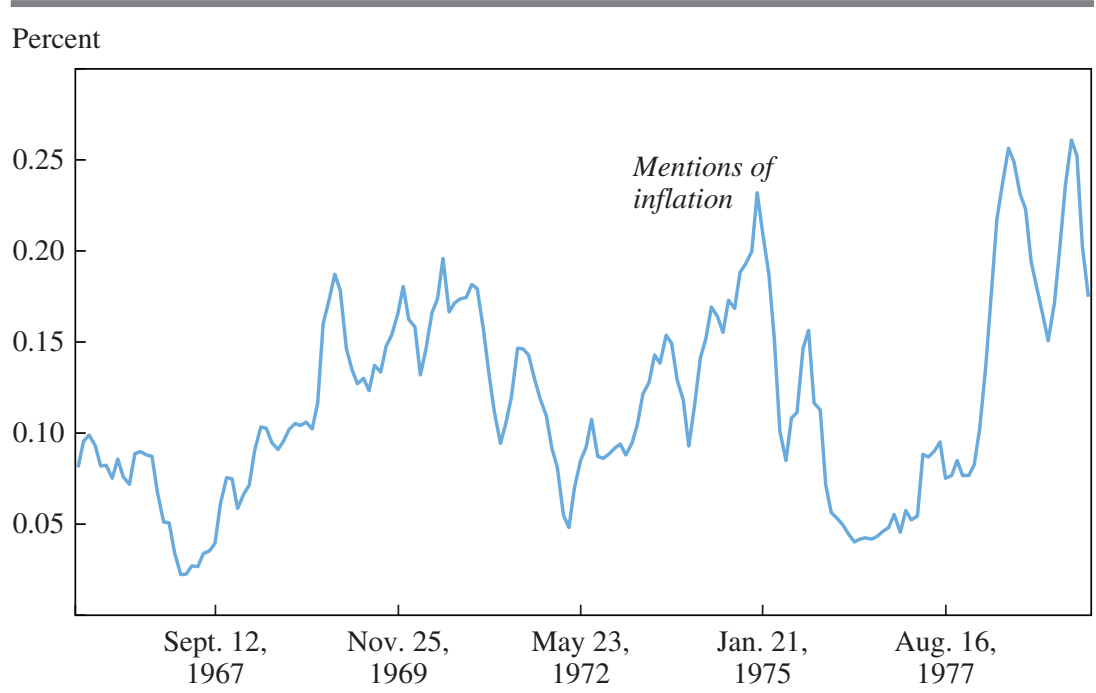

Source: Federal Reserve Board.

a. Four-meeting moving-average term counts as a percentage of total words in FOMC transcripts, memorandums of discussions, and historical minutes.

the policy framework. By the end of the 1960s, the need to design monetary policy to account for the requirements of fiscal policy and the executive branch-particularly given the increases in spending on the Vietnam War-had produced disappointing inflation outcomes. ${ }^{10}$ The FOMC's nervousness about the inflation situation at that time can be inferred from an increase in the mentions of inflation, as shown in figure $3 .{ }^{11}$ Policy tightening in 1969 was seen as an opportunity to reduce inflation. However, the realized decline was noticeably less than expected. Figure 4 shows that the persistent miss in the inflation forecast at the time cannot

10. At the January 1969 FOMC meeting, Chairman William McChesney Martin mentioned that "to Mr. Nixon, he had expressed his view that inflation was the primary economic problem now facing the nation, and that the new Administration would have to deal with it effectively from the beginning if inflation were not to get out of control. He had done his best to emphasize the seriousness of the problem" (Minutes, January 14, 1969).

11. It is important to note that the terms used to discuss similar topics have changed throughout U.S. monetary history. Thus, the use of "inflationary psychology" was fairly common in the 1960s but is less common today. More commonly used terms included "inflation expectations" and the "anchoring" of expectations. For this reason, we must take care in interpreting the frequency with which specific phrases are used. 
Figure 4. Federal Reserve Greenbook Forecasts, 1969:Q2-1970:Q3

Forecasts of inflation

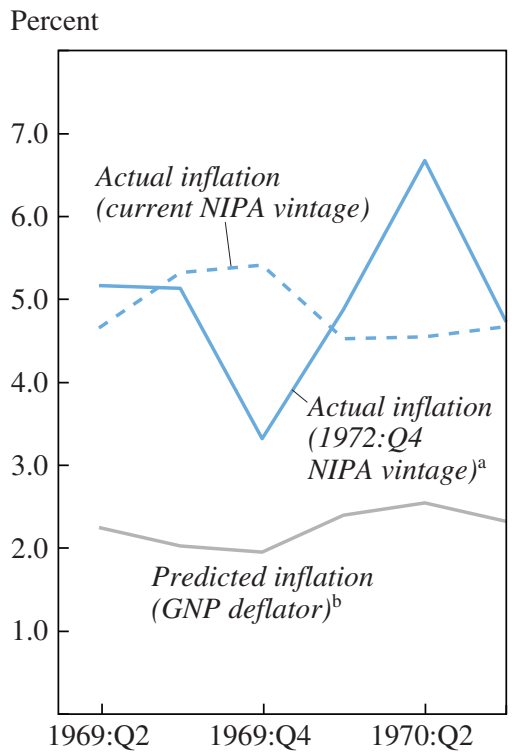

Forecasts of the unemployment rate

Percent

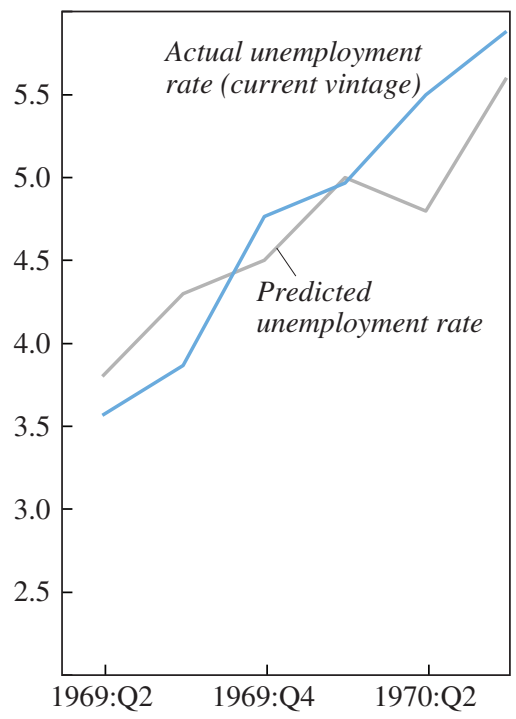

Sources: Bureau of Economic Analysis; Bureau of Labor Statistics; Federal Reserve Board; Haver Analytics.

a. NIPA $=$ National Income and Product Accounts.

b. GNP = gross national product.

be attributed to a persistent downward bias in the unemployment rate forecast. $^{12}$

The inflation underprediction appears to have led to a reconsideration of the Fed's inflation model. The increase in the weight given to past inflation in equation 1 in the early 1970s signals a move toward an accelerationist view of inflation..$^{13}$ The estimates of $\beta_{1, t}$ do not reach unity in equation 1 because, with time-varying coefficients, some of the persistence in the inflation process is shifted from lagged inflation to the time-varying intercept. But

12. The horizontal axis in the graphs denotes the quarter in which the Greenbook forecast was made. The forecast is given by the value of inflation or the unemployment rate expected to prevail on average three and four quarters into the forecast. We use only the third quarter of the forecast whenever the fourth quarter is not available. The exercise stopped with the 1970:Q3 forecast because the Nixon wage and price controls were enacted in 1971:Q3.

13. Sargent (2001) attributes the run-up in inflation in the late 1960s and 1970s to slow learning about the true process of inflation. 
a fixed-coefficients estimation of equation 1 over a period spanning from the 1970s to the early 2000s would yield a coefficient on lagged inflation very close to unity, which is consistent with the Friedman-Phelps natural rate framework. This change, coupled with a decline in the short-run tradeoff between inflation and unemployment, entailed a significant increase in the perceived sacrifice ratio during the mid-1970s. Note that an increase in $\beta_{1, t}$ from 0.2 to 0.8 and a decline in the absolute value of $\beta_{2, t}$ from 0.4 to 0.25 - which is roughly the magnitude of the movements that occurred from the late 1960s to the mid-1970s-imply that bringing inflation down from 5 to 4 percent over the course of eight quarters would require, other things being equal, an unemployment rate gap of about 1 percent on average, up from 0.2 percent.

This pessimism about the cost/benefit trade-off of using monetary policy to lower inflation has been documented before (for example, by Romer and Romer 2013). As a consequence, beginning in the early 1970s, price and wage controls were advocated as an alternative means for controlling inflation, and figure 5 highlights how FOMC members were discussing such fiscal solutions to the inflation problem. The reluctance to engineer large employment losses as a way of reducing inflation had notable implications for another aspect of the framework, the inflation target. In the context of equation 1, it is possible to infer the FOMC operational inflation target from the time-varying intercept, which can be written as

$$
\beta_{0, t}=\left(1-\beta_{1, t}\right) \pi_{t}^{*}-\beta_{2, t} \bar{u}_{t},
$$

where $\pi_{t}^{*}$ and $\bar{u}_{t}$ are time-varying measures of longer-run inflation and the natural rate of unemployment, respectively. Together, equations 1 and 2 provide a representation of the Phillips curve, which is now often used to parsimoniously describe inflation. Although this is a "modern" view of the inflation process, a looser interpretation in terms of a reduced form where inflation has a tendency to revert over the forecast horizon to the $\pi_{t}^{*}$ objective-after controlling for an activity gap and supply shocks-is still valid and likely to have informed the Federal Reserve's inflation forecast consistently over time.

Figure 6 depicts a derivation of $\pi_{t}^{*}$ according to equation 2, given our estimated time-varying $\beta$ s under the assumption that the natural rate of unemployment, $\bar{u}_{t}$, evolves as in the most recent vintage of the CBO's estimate, over the period 1969-2007. The current vintage of the CBO's natural rate of unemployment differs from real-time estimates, and such a 
Figure 5. Mentions of Fiscal Solutions to the Inflation Problem, 1960-2012a

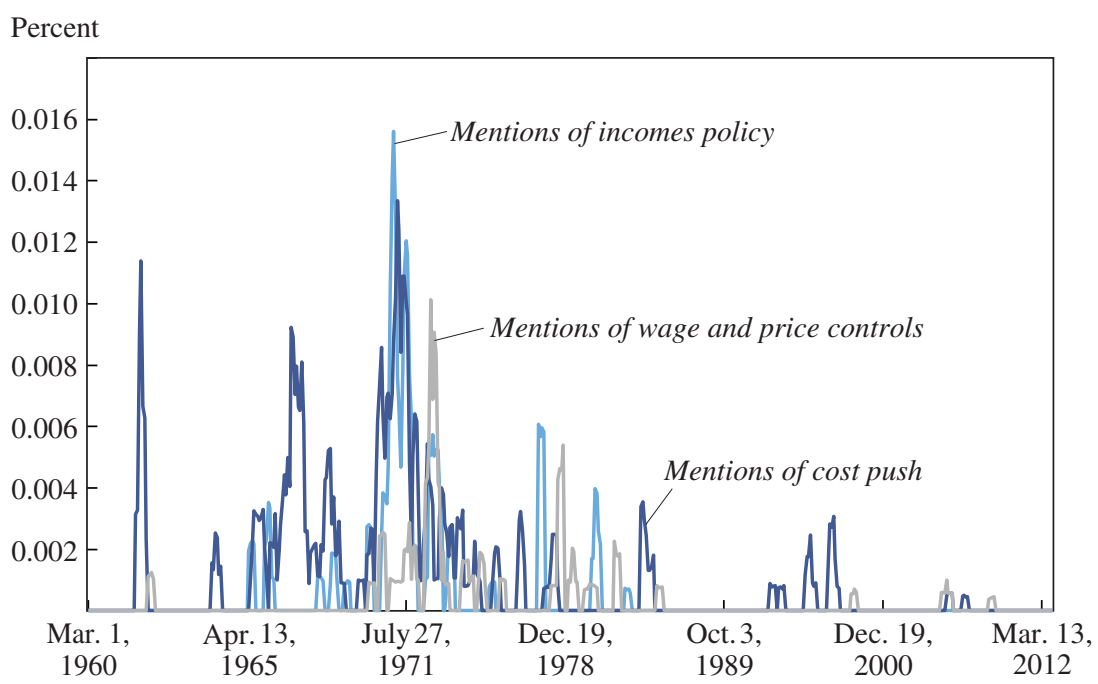

Source: Federal Reserve Board.

a. Four-meeting moving-average term counts as a percentage of total words in FOMC transcripts, memorandums of discussions, and historical minutes.

Figure 6. Estimated Longer-Run Inflation, 1968:Q4-2007:Q4

\section{Percent}

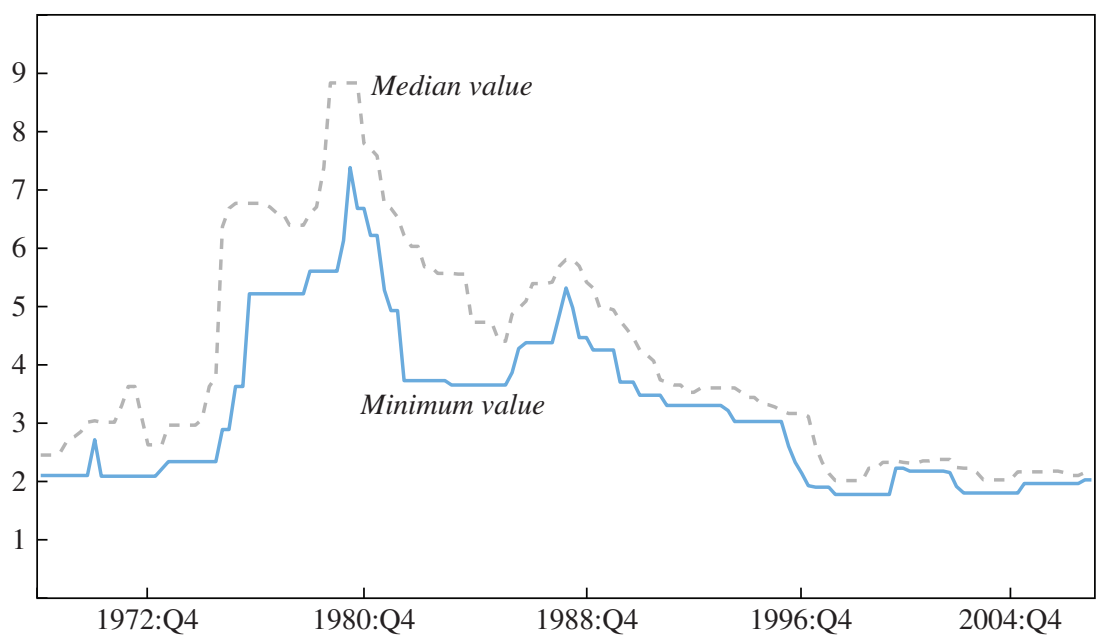

Sources: Authors' calculations; Congressional Budget Office; Federal Reserve Board. 
difference will introduce biases in the estimate of $\pi_{t}^{*}$, a point to which we return below. Because the estimated time-varying parameters are noisy, figure 6 depicts the minimum and median values of $\pi_{t}^{*}$ over a centered moving window of nine quarters. We report the minimum value to provide a conservative assessment of the time variation in $\pi_{t}^{*}$.

The main takeaway from this exercise is that the attainable rate of inflation in the medium term was subject to profound reevaluations in the late 1960s and the 1970s. Furthermore, the tolerable level of inflation was also subject to reevaluations that continued until the late $1990 \mathrm{~s}$, when $\pi_{t}^{*}$ finally settled at about 2 percent. The figure depicts a steady increase in the implicit inflation goal over the course of the 1970s. Because the CBO's current view of the natural rate of unemployment in the 1970s is likely higher than most real-time assessments, our estimate of the rise in the inflation goal over this period is conservative. ${ }^{14}$ It is possible that policymakers' long-run aspirations were always for low inflation, but in practice their perception of the attainable rate of inflation in the medium run was subject to frequent reevaluations in the face of adverse supply shocks. ${ }^{15}$ Without a clear mandate, the costs of returning to a lower target were considered too high to be paid directly, a topic that is further addressed when we discuss "opportunistic disinflation." Needless to say, the lack of explicit targets was a significantly important missing piece to the monetary policy framework in the 1970s. But it is also important to note that the target was subject to, admittedly milder, revisions in the 1980s and most of the 1990s. By then, the Federal Reserve had regained credibility in its stance toward inflation; but as we discuss below, it was not yet transparent about its inflation goal.

From an inflation model perspective, the most recent period also stands out. The role for past inflation and economic slack in determining inflation has diminished, and more emphasis is placed on long-run inflation expectations. Figure 7 shows that discussions about "well-anchored expectations" increasingly appear in the transcripts starting in 2004. With a stable inflation goal at 2 percent, the focus was to maintain inflation near

14. In deriving our estimate of the inflation goal from equation 2, we have purposely chosen the CBO's estimate because it averages about 6.0 percent in the $1970 \mathrm{~s}$, with relatively little variation over the decade. This estimate is likely on the high side of the range of real-time estimates of the natural rate of unemployment, and therefore makes the reported $\pi_{t}^{*}$ in the 1970 s a conservative estimate.

15. Ireland (2007) reaches similar conclusions about time variation in the inflation objective using a different approach based on estimating a small-scale, dynamic stochastic general equilibrium model on actual data. 
Figure 7. Mentions of Well-Anchored Inflation Expectations, 1960-2012

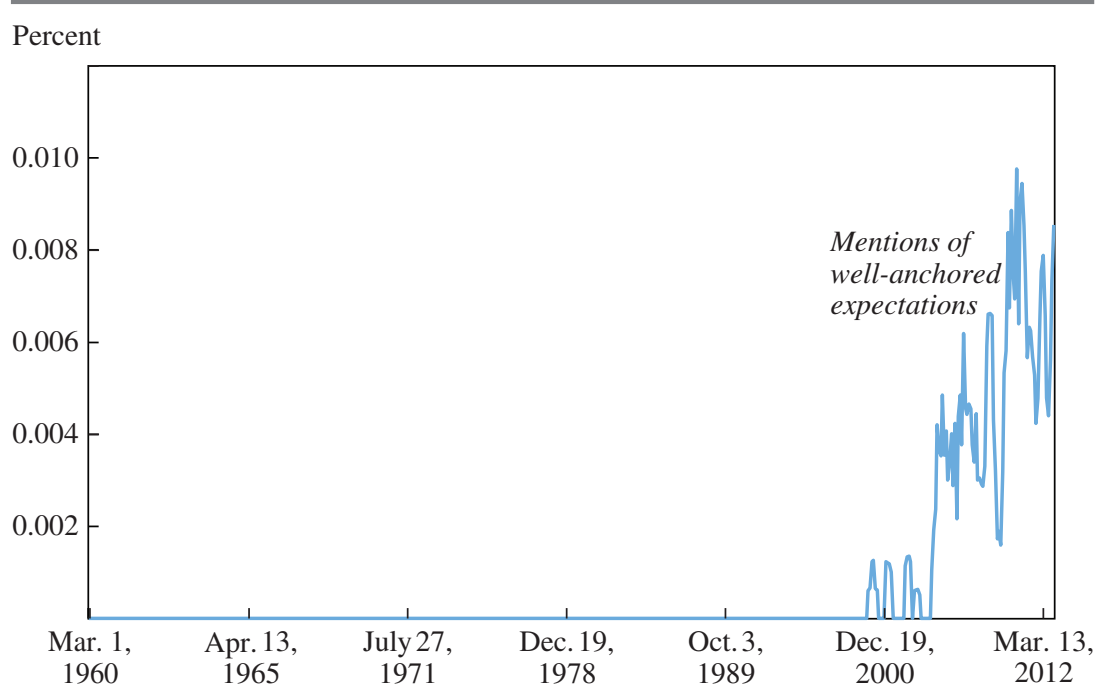

Source: Federal Reserve Board.

a. Four-meeting moving-average term counts as a percentage of total words in FOMC transcripts, memorandums of discussions, and historical minutes.

this target rather than to achieve lower inflation. The notion here is that insofar as long-run inflation expectations are "well-anchored," inflation will deviate only modestly from the inflation goal in proportion to the deviation of the unemployment rate from its equilibrium level. In this context, the role of the central bank is to ensure that long-run expectations are centered on the inflation goal, and to stabilize the economy at full employment, at which point inflation will equal its target.

As is discussed later in this paper, the anchoring power of long-run expectations and the small effect of the unemployment rate gap on realized inflation have important repercussions for the monetary policy framework. The inflation costs of deviating from full employment are small in this setup. As a result, the cost/benefit analysis of probing for better labor market outcomes (in the form of a lower equilibrium unemployment rate) may be more favorable now. Issues surrounding the shape of the loss function are also coming into better focus. With small inflation costs, what are the welfare costs of overshooting full employment? Are the losses symmetric to undershooting full employment, as the current statement on monetary policy strategy implies? 


\section{II.B. Changes in Policy Rules and Opportunistic Disinflation}

As the target-less regime began to crumble by the end of the 1970s, the passage of the Humphrey-Hawkins Act of 1978 provided the Federal Reserve with a mandate to pursue targets—but not a road map for how to get there. Along with calling for semiannual reports to Congress, the Humphrey-Hawkins Act amended the monetary policy objectives contained in the Federal Reserve Act, and thus directed the FOMC to "maintain long run growth of the monetary and credit aggregates commensurate with the economy's long run potential to increase production so as to promote effectively the goals of maximum employment, stable prices, and moderate long-term interest rates." The 1979 monetary aggregates experiment could be looked at in the context of just such a road map or rule. More generally, the topic of how a policy rule for the FOMC has evolved over time has been widely debated in the literature. To capture time variation in the policy rule, we consider this reaction function:

$$
f f_{t}=\gamma_{0, t}+\gamma_{f f, t} f f_{t-1}+\gamma_{\pi, t} E_{t} \pi_{t+3}+\gamma_{u t,} E_{t} u_{t+3}+v_{t},
$$

where $f f$ is the federal funds rate and the other variables are defined as above, with $v$ denoting the error term. ${ }^{16}$ The rule is forecast-based, with the forecasts being given again by the Fed staff's projections as published in the GB/TB. In addition to the forecasts of inflation and unemployment, the rule allows for smoothing interest rates. As before, the coefficients in the rule are time-varying, with their evolution assumed to follow a random walk.

Equation 3 is estimated over the sample from 1969:Q1 to 2008:Q4; more details about the data and estimation are provided in the appendix. Figure 8 reports the unsmoothed filtered estimates starting in 1973:Q4. We omit the earlier period because the estimates might be affected by the choice of initial conditions, for which we do not hold strong priors. The figure also reports the long-run responses to inflation and unemployment, computed by dividing the contemporaneous responses by $1-\gamma_{f, t}$. In all,

16. The specification is similar to that given by Boivin (2006). Our exercise, however, is conducted at a quarterly rather than at a Greenbook frequency. Another important difference is that we let the time-varying intercept capture not just potential changes in the equilibrium federal funds rate but also changes in policymakers' assessment of the natural rate of unemployment. 
Figure 8. Unsmoothed Estimated Coefficients for Equation 3, 1973:Q4-2008:Q4

Filtered state $\gamma_{0}$ estimate

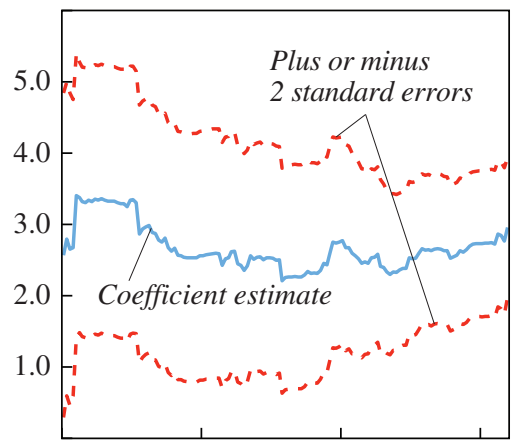

1973:Q4 1984:Q4 1995:Q4 2006:Q4

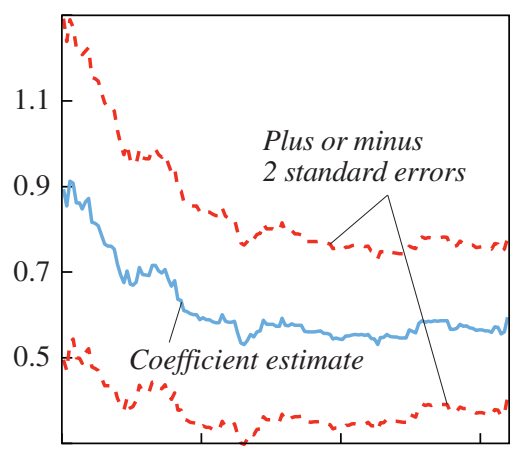

1973:Q4 1984:Q4 1995:Q4 2006:Q4

Long-run inflation response

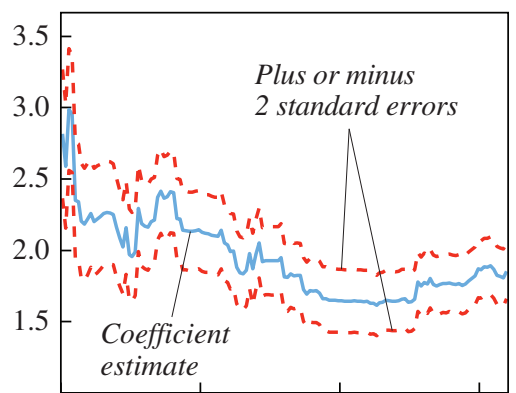

1973:Q4 1984:Q4 1995:Q4 2006:Q4

Filtered state $\gamma_{f f}$ estimate

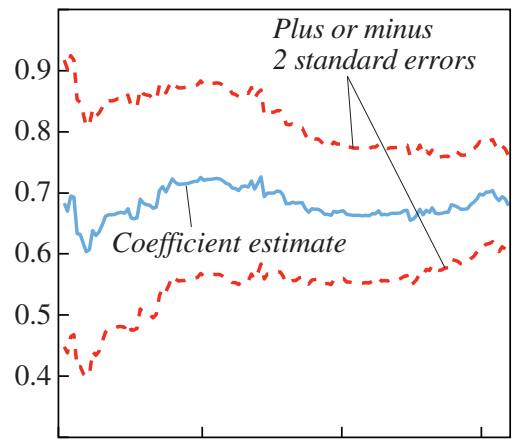

1973:Q4 1984:Q4 1995:Q4 2006:Q4

Filtered state $\gamma_{\mu}$ estimate

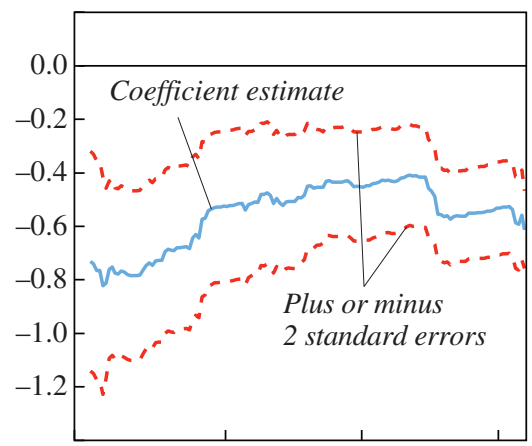

1973:Q4 1984:Q4 1995:Q4 2006:Q4

Long-run unemployment response

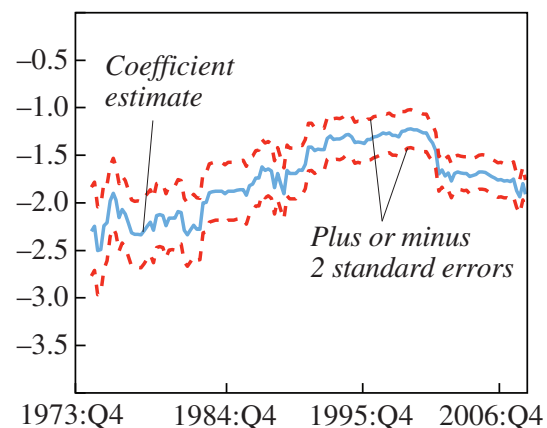

Sources: Authors' calculations; Federal Reserve Board. 
there has been some variation over time in the degree of interest rate smoothing and in how the FOMC has reacted to inflation and unemployment rate forecasts.

It is interesting to note that the weight given to unemployment relative to inflation (in absolute terms) was, overall, at its largest in the 1970s, and then declined in the 1980s and the 1990s. The relative emphasis on unemployment deviations in the 1970s is consistent with the previous discussion about the FOMC being unwilling to generate large employment losses in order to reduce inflation. Such a focus on employment stabilization also raises the much-discussed issue of the Fed's independence. Still, once taking into account changes in the operational inflation target (which, in the context of the policy rule given in equation 3, are subsumed in $\gamma_{0, t}$ ), the tenet that in the 1970s the FOMC was violating the "Taylor principle," whereby policy rates move more than one-for-one with inflation, is far from settled. ${ }^{17}$ In our exercise, the long-run response of the federal funds rate to inflation projections is always estimated to be above unity. ${ }^{18}$

The estimated parameters in equation 3 signal a greater emphasis placed over the course of the 1980s and 1990s on deviations of inflation from target relative to deviations from full employment. After the sharp decline in inflation achieved by 1984, it is notable how the strategy over most of the years 1984-86 was one with a strong resemblance to a gradualist approach to driving inflation lower. During those years, the unemployment rate was stable, but at levels near 7 percent, above the natural rate. A variant of this strategy was later undertaken under Alan Greenspan in the late 1980s and early 1990s, with the FOMC pursuing "opportunistic disinflation" to reduce inflation below its average of 3.5 to 4 percent. The strategy accomplished a reduction in inflation by allowing some slack to remain in the economy following the 1990-91 economic downturn, avoiding the arguably larger costs of initiating another recession. It is possible to motivate such a strategy by assuming an unconventional loss function in employment and inflation (see Orphanides and Wilcox 2002), a notion that hints at the flexible

17. For contrasting views about the FOMC rule's consistency with the Taylor principle in the 1970s, see, for example, Clarida, Galí, and Gertler (2000); and Orphanides (2003). Boivin (2006) reaches different conclusions from ours, likely as a result of the differences in the specifications that we have already discussed.

18. In this regard, it is relevant to note that the effective federal funds rate increased substantially in 1973 before the oil price shock. And monetary policy had tightened already in 1978 and 1979, before Paul Volcker became chairman. 
interpretation of the loss function underlying the FOMC's policy framework during this period. ${ }^{19}$ The literature in the late 1980s and early 1990 s was already examining the benefits of transparency. This is one instance when a regular conference on the framework during this period might have raised the issue of opportunism more clearly and fostered more discussion about transparency.

In the more recent period covered in the exercise, which spans from the 2000s to the onset of the Great Recession, the long-run response to unemployment has increased again in absolute value, with inflation and unemployment deviations carrying about the same weight in the reaction function. It is possible that the anchoring of inflation expectations and a "flat Phillips curve" have played a role in such a development. Here, we note that an optimal policy exercise with a credible inflation target would be consistent with a larger weight given to activity stabilization in a policy reaction function such as equation 3, when the slope of the Phillips curve becomes flatter (see, for example, Iakova 2007; Erceg and others 2018).

The time-varying nature of the reaction function given in equation 3 makes it complicated to talk about rules versus discretion, in that a changing unemployment response relative to inflation, or changes to the interest rate smoothing coefficient, could be interpreted as an exercise in discretion. Nevertheless, even with this flexible setup, it is possible to identify other important changes in the conduct of policy. In particular, figure 9 depicts the estimated error term $v$ in the policy function. The dotted part of the line encompasses a period of high volatility in the early part of Paul Volcker's tenure associated with the operating procedure for nonborrowed reserves. Overall, it is apparent that the predictability of the rule has increased noticeably since the mid-1980s.

Another notable feature of the current policy environment is that changes in the policy rule are key to explaining the conduct of monetary policy after the liftoff from the zero lower bound. Figure 10 plots the predicted federal funds rate using the coefficients in equation 3 as estimated in 2008:Q4, vis-à-vis the actual, from 2015:Q4 to the present. ${ }^{20}$ The simulation is static, in that it uses the actual lagged federal funds rate. Despite such a feature, it

19. This reverse engineering exercise posited a loss function in the absolute value of unemployment and the squared deviation of inflation from a short-run inflation target. This loss function induces a region of inactivity for sufficiently small inflation deviations. In these circumstances, the central bank optimally waits for a shock that moves inflation toward the long-run goal, pocketing gains along the way without deliberately altering the output gap.

20. Because the forecasts from the board staff are not yet publicly available, we use instead the FOMC's "Summary of Economic Projections." 
Figure 9. Estimated Error Term in the Policy Rule Given in Equation 3, 1973:Q4-2008:Q4

Percent

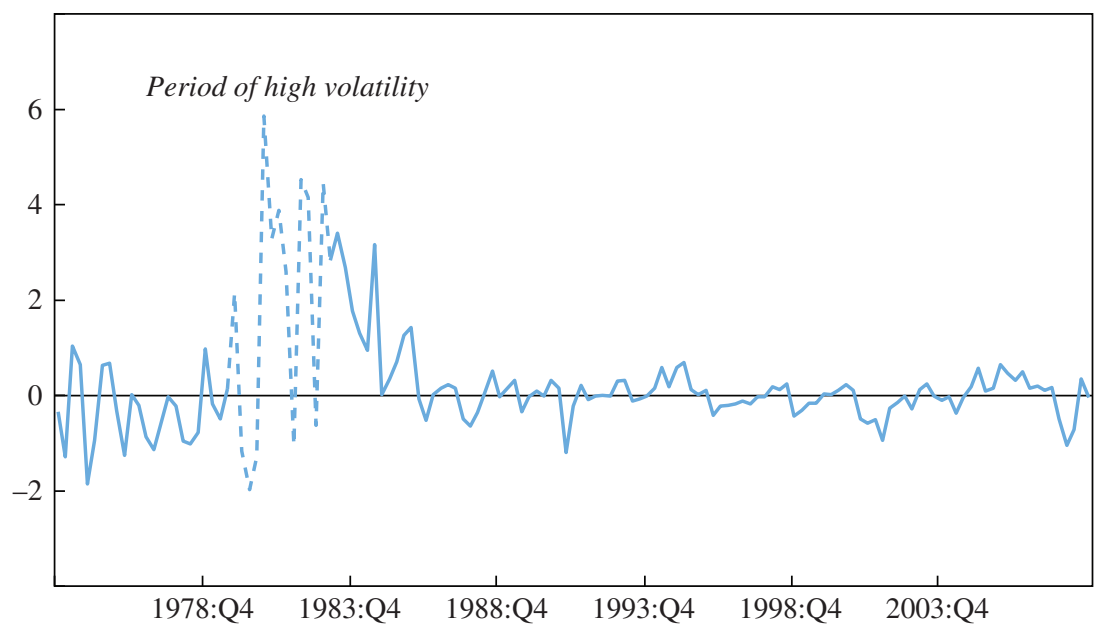

Sources: Authors' calculations; Federal Reserve Board.

a. Noise in the policy rule, as captured by $v$.

Figure 10. Actual and Predicted Federal Funds Rate Targets, 2015:Q4-2018:Q2

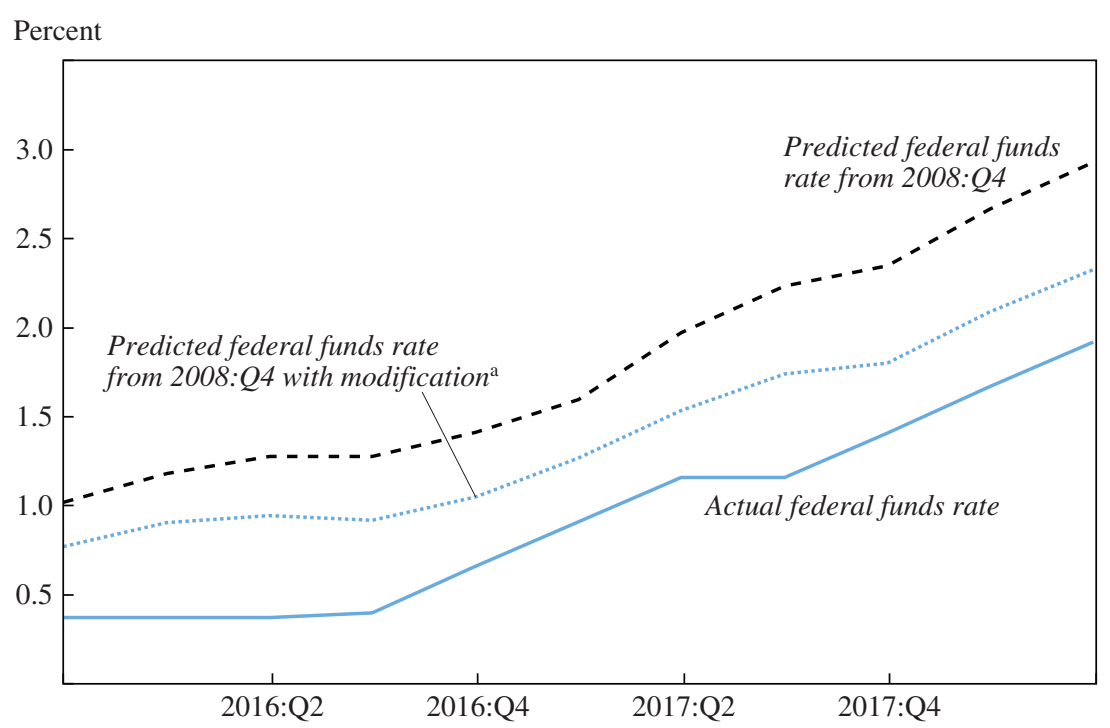

Sources: Authors' calculations; Federal Reserve Board.

a. Predicted from 2008:Q4 with a modified constant to account for long-run values estimated by the "Summary of Economic Projections." 
is apparent that the reaction function given in equation 3 with the 2008:Q4 estimated coefficients is a poor predictor of the FOMC's behavior in the most recent period. Modifying the intercept in equation 3 to account for changes in the assessment of the equilibrium value of the federal funds rate and the unemployment rate-as reported in the "Summary of Economic Projections" (SEP) over the simulation period-reduces but does not eliminate the difference. In other words, a decline in the estimate of the equilibrium federal funds rate has played an important role, but other factors have also been at play. These factors could be related to risk management considerations, and/or to shifts in the weights assigned in the rule to unemployment and inflation deviations. The potential for such shifts would point again to a flexible interpretation of the loss function underlying the FOMC's policy framework.

\section{II.C. The Fed's Transparency and Credibility}

The changes discussed so far to the policy framework in terms of the inflation goal and the systematic component of policy are also related to other elements of the framework, most notably transparency and the efficacy of Fed actions. In this regard, Refet Gürkaynak, Brian Sack, and Eric Swanson (2005) find evidence of excess sensitivity of longer-dated forward rates to economic news, which they argue is indicative of the public having to learn about the monetary authority's inflation target. ${ }^{21}$ More broadly, changing long-term inflation expectations could result from policymakers' lack of transparency or lack of credibility. Here, we revisit the relationship between a short-run spot interest rate and forward rates in the days when the Consumer Price Index (CPI) or the Producer Price Index (PPI) were released, and compare this reaction with nonrelease dates:

$$
\begin{aligned}
\Delta i_{t}^{F, j}= & \alpha_{0}+\alpha_{1} \Delta i_{t} d_{t}(\text { release day }=1) \\
& +\alpha_{2} \Delta i_{t}\left(1-d_{t}(\text { release day }=1)\right)+\varepsilon_{t} .
\end{aligned}
$$

The dependent variable $\Delta i_{t}^{F, j}$ is the daily change in the Treasury forward rate $j$ years ahead, whereas the explanatory variable $\Delta i_{t}$ is the daily change in the spot three-month Treasury bill yield. The dummy variable $d_{t}$ takes the value of 1 on days when there was a CPI release or a PPI release,

21. Kozicki and Tinsley (2001), though not focusing specifically on economic news, also argue that movements in forward rates at the longer end of the maturity spectrum have been related to shifts in market perceptions of the policy target for inflation. 
Figure 11. Estimated Coefficients for Equation 4, 1970-96 and 1997-2007

Estimated coefficients for 1970-96

Percent

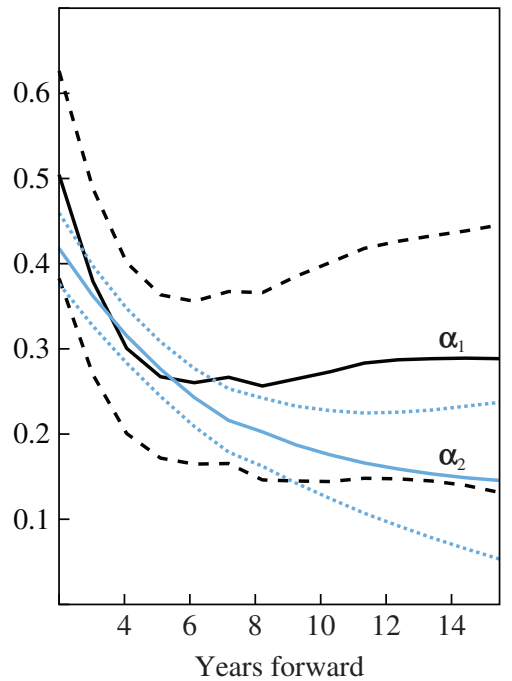

Estimated coefficients for 1997-2007

Percent

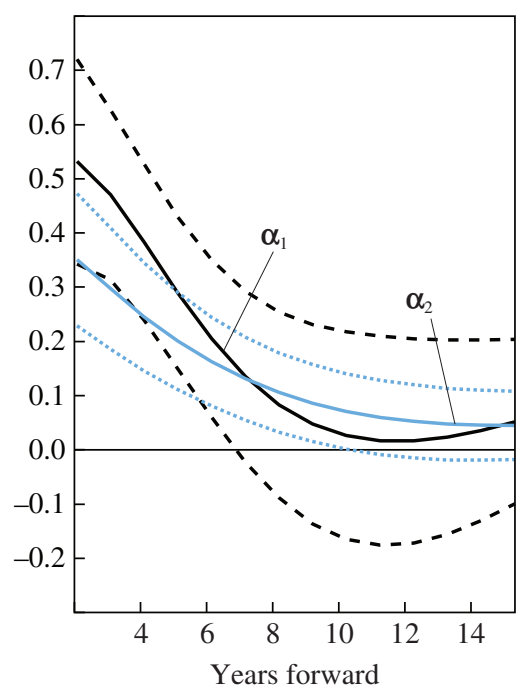

Sources: Authors' calculations; Federal Reserve Board. a. The dashed lines are plus or minus 2 standard errors.

and a value of zero on the other days. The specification assumes that on release dates, the change in the spot three-month Treasury bill captures the "news" effect of the CPI or PPI release, and that the effect of the release on the forward rates can be assessed from its impact on the spot rate. ${ }^{22}$ We consider instantaneous forward rates spanning the maturities from 2 to 15 years ahead. ${ }^{23}$ Near-term forward rates will be affected by cyclical variables, including expectations about monetary policy actions. Longerterm forward rates are determined by more persistent factors, including expectations about policymakers' target for inflation.

Figure 11 reports estimation results for the coefficients $\alpha_{1}$ and $\alpha_{2}$ in equation 4 over two subsamples. The periods we consider are 1970-96

22. This assumption allows us to circumvent the issue of not being able to measure the news effect of the release using market survey data in the period before the 1990s. We focus on inflation release dates because these should capture potential shifts at the longer end of the maturity spectrum that are motivated by shifts in perceptions about the long-run inflation objective.

23. More detail about the data and estimation is provided in the appendix. 
and 1997-2007. ${ }^{24}$ The sample split is informed by our previous inference on the FOMC's inflation objective. For the longer-dated forward rates, the reaction to inflation news is stronger than on nonrelease dates- that is, the heavier line is above the lighter line, or $\alpha_{1}>\alpha_{2}$-in the 1970-96 period. We take this finding as consistent with the view that since the 1970s and up until the late 1990s, financial markets had changing perceptions about the FOMC's inflation goal, with those perceptions being influenced by news about inflation. The exercise cannot assess whether the way the public was revising expectations about the FOMC's inflation objective was consistent with the FOMC's changing target $\pi_{t}^{*}$ as depicted in figure 6 . Still, a lack of transparency about the inflation goal could have affected movements at the longer end of the expectations curve, an indication of the markets' lack of confidence in the Fed's commitment to bring inflation to a specific, well-understood inflation target. The more recent period, with no significant response of longer-dated forward yields to changes in the short-term Treasury bill both on inflation release dates and on nonrelease dates, is consistent with the public perceiving the policymaker as having a credible and stable inflation target.

Needless to say, this exercise provides at best partial answers to the evolution of the Fed's transparency over time. And the findings for the 1970s and 1980s could have different interpretations. It is possible, for example, that the excessive reaction to inflation news at the longer end of the term structure was also a symptom of a lack of credibility in the 1970s. In the 1980s and early 1990s, the reasons for such a result could be different, and hinge not on the Fed's credibility in its stance about inflation but on the FOMC's vagueness about its long-run inflation goal. Nevertheless, the results suggest that the steps taken to increase credibility and transparency over time took long to manifest themselves in the form of the long end of the term structure becoming unresponsive to short-run inflation news. One potential reason for this finding is that the move toward increased credibility and transparency was incremental.

It is possible to identify a number of steps in this incremental process. The Humphrey-Hawkins Act of 1978 certainly increased transparency and solidified the importance of the dual mandate. This act clarified the goals of monetary policy, increased accountability to Congress, and provided an opportunity for a more transparent discussion of monetary policy actions.

24. We use daily data from the 1970 s to the end of 2007 , and exclude the more recent period because of the complications associated with the conduct of monetary policy at the zero lower bound. 
Figure 12. Mentions of the Federal Reserve's Credibility, 1960-2012a

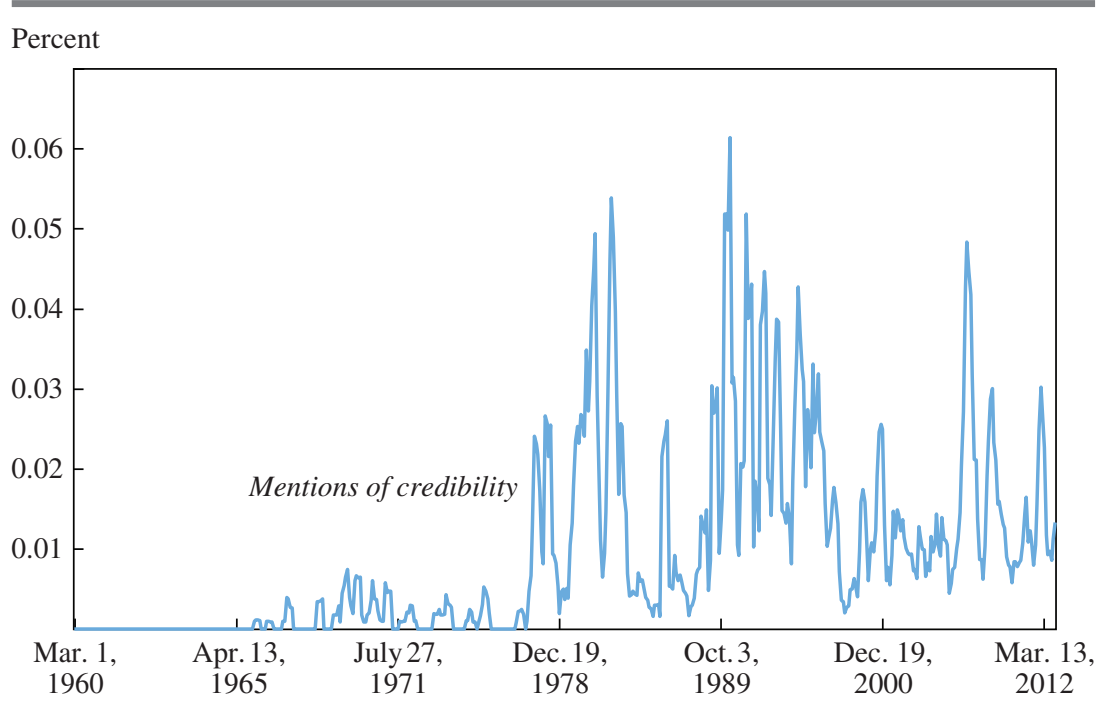

Source: Federal Reserve Board.

a. Four-meeting moving-average term counts as a percentage of total words in FOMC transcripts, memorandums of discussions, and historical minutes.

And the detailed account given by Marvin Goodfriend and Robert King (2005) of the Volcker disinflation highlights Volcker's understanding of the importance of credible monetary policy actions vis-à-vis financial markets, and in particular the role of credibility in informing markets' expectations about inflation in the medium and longer runs. Figure 12's word counts show an increasing number of discussions at the FOMC table about credibility. Over time, this development led to important changes in the conduct of monetary policy. As discussed above, monetary policy actions became more predictable and more clearly anchored to the dual mandate goals.

Throughout the 1990s, several changes occurred regarding the transparency of monetary policy. The first tentative step toward greater transparency occurred in 1994, when the Federal Reserve began to include the intended change in the federal funds target in its statement. Although most financial market participants had been aware of the focus on the federal funds rate since 1987 or earlier, the Fed simply did not announce its new funds target before 1994. The adoption of a target of roughly 2 percent was discussed and agreed upon internally by the FOMC in 1996. From a transparency standpoint, it is interesting that such a target was not initially 
made explicit to the public. It is possible that greater transparency was perceived as potentially carrying a credibility cost if that 2 percent target were subject to change at a future date. Another move toward greater transparency and predictability occurred during the slow recovery from the 2001 recession. By the late summer of 2003, the Fed had hit what it assumed was its effective lower bound. Given the low rate of inflation at the time, the FOMC indulged in rudimentary "forward guidance," which was meant to provide the markets with its view of future policy actions.

Other important improvements to transparency have occurred during the most recent period, which is not covered in our empirical exercise. Forward guidance became a crucial element in the conduct of monetary policy when the federal funds rate was at the effective zero lower bound. In addition, the Federal Reserve began to hold quarterly press conferences to explain its policy actions to the public, and recently the Fed announced that these press conferences will be conducted after each meeting. Perhaps most important, starting in 2012 the FOMC provided a document explicitly outlining its monetary policy framework, including an explicit 2 percent inflation target. This framework document is explicitly voted on at the January meeting, and it certainly provides an annual opportunity to communicate changes in the monetary policy framework. However, more extensive, comprehensive, and public discussions of the policy framework, such as those conducted by the Bank of Canada, have not yet emerged through this process.

\section{II.D. Other Strands of the Framework}

The empirical exercises so far have highlighted some, but not all, of the relevant changes to the monetary policy framework. One important element that has not been discussed so far is the role of financial stability in monetary policy. For an empirical examination of how financial stability has affected the conduct of monetary policy over time in the context of a reaction function similar to the one considered in equation 3 , we refer the reader to the research of Joe Peek, Eric Rosengren, and Geoffrey Tootell (2015). An enduring effect of the late-1990s "productivity revolution," which was used as justification for the significant boom in equity prices relative to earnings, was an increase in the attention paid to asset prices and (more generally) financial stability in the policy discussion, as shown in figure 13. This focus subsided somewhat after the 2001 recession, which was caused in part by a significant reduction in prices of Internet-related stocks, but it was a precursor to the renewed focus on financial stability issues following the 2008 financial crisis. It is reasonable to view increased 
Figure 13. Mentions of Financial Stability in the Policy Discussion, 1973-2009a

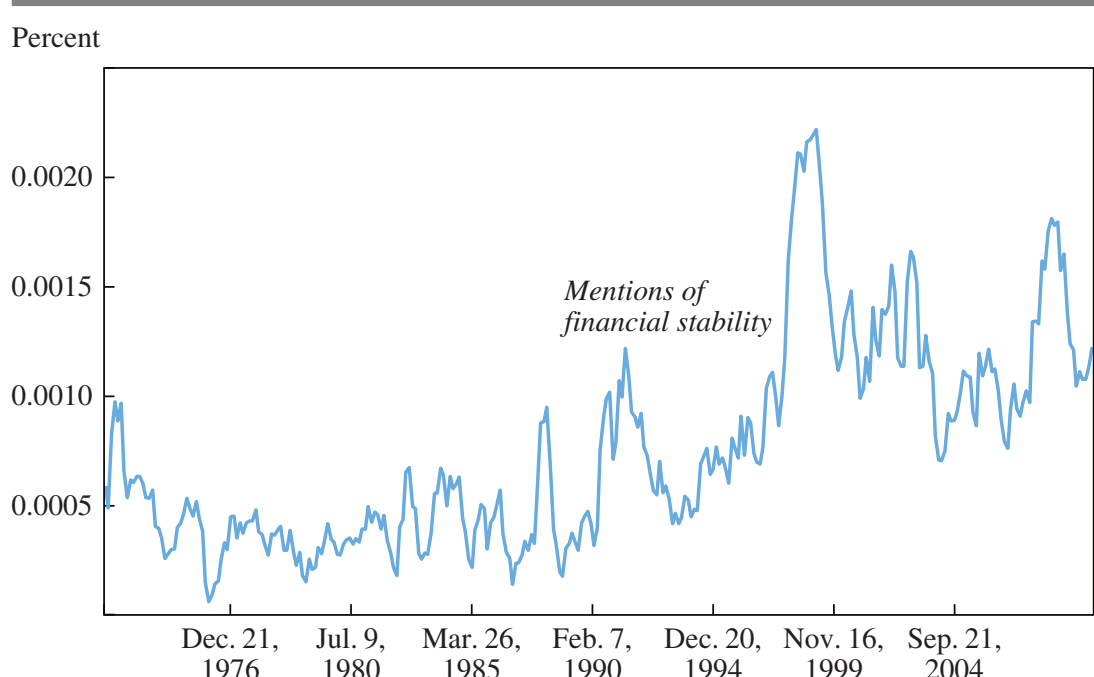

Sources: Federal Reserve Board; Peek, Rosengren, and Tootell (2015).

a. Four-meeting moving-average term counts as a percentage of total words in FOMC transcripts, memorandums of discussions, and historical minutes.

attention to financial stability issues as a change in framework, tantamount in its extreme version to the adoption of a "ternary mandate."

The other aspect of the evolution of the framework is more technical, and pertains to the instrument or set of instruments used for the conduct of monetary policy. A full discussion of these tools is beyond the scope of this analysis. Ben Bernanke (2006) provides a historical perspective on the use of monetary aggregates as a guide for monetary policy, and their eventual demise in favor of the federal funds rate as the primary tool of monetary policy. Nevertheless, it is important to highlight the use of the balance sheet as a policy tool during the Great Recession and the ensuing recovery, when the federal funds rate was at the effective zero lower bound. The way one judges the efficacy of those asset purchases has consequences for the urgency with which one perceives that the current framework needs to be changed.

\section{II.E. Why Have a Formal Framework Review?}

Overall, it seems reasonably clear that the monetary policy framework has changed along several important dimensions since the late 1960s. 
Some changes occurred rapidly when necessitated by acute economic conditions, such as the Volcker disinflation. Other framework changes were considered and implemented gradually under relatively benign economic conditions as a response to long-standing problems with the framework, such as increases in transparency.

Concerning the merits of a formal framework review, several observations can be drawn from our historical assessment of framework changes. First, some of the past shortcomings in the conduct of monetary policy can be ascribed to missing elements of the framework laid out in section I. The lack of clarity on an inflation goal in the late 1960s and early 1970s contributed to a mix of fiscal and monetary policies in which output stabilization became the primary focus, and in which the responsibility of the central bank for price stability was more ambiguous. This subordination may also have been a consequence of the lack of independence and credibility at the time in pursuing monetary policy actions to reduce inflation. These issues were later exacerbated by bad luck in the form of a number of adverse supply shocks, with the stabilization of inflation again taking the backseat, in part because the sacrifice ratio was perceived as being too high.

Other elements of the framework came into being in different ways. With the Humphrey-Hawkins Act, Congress specified the dual goals of monetary policy. But it was Fed chairman Paul Volcker who ultimately reclaimed the role of monetary policy in controlling inflation. Although we have shown that the implicit inflation target under Volcker was subject to change, the direction of the change was unmistakably toward lower inflation, even if the disinflation was a bit "opportunistic." Another element of the framework that emerged under Volcker (after the nonborrowed reserves operating procedure) was greater predictability of Fed actions. These elements in the conduct of policy were largely cemented under Greenspan's chairmanship. Others came into focus later, and largely had to do with a better appreciation of the role of expectations and the associated importance of transparency in communicating long-run goals and policy intentions. In sum, many key elements of the framework that have been put in place have had an evolutionary aspect. The evolution of economic thinking and the lessons gleaned from historical experience have been instrumental in providing a better understanding of the ways to improve central bank design (Blinder 1998; Reis 2013). This evolution of our understanding of monetary policy exemplifies one way in which regular conferences might be helpful. 
Second, it is interesting to note that the significant change in approach to policy taken under Volcker occurred with an essentially unchanged FOMC. Thus, this episode provides a stark example of the FOMC chair's crucial role in policymaking. It is notable that accounts of the history of U.S. monetary policy often identify regimes or frameworks with the FOMC chair at the time (for example, Romer and Romer 2013). Although our account of relevant framework changes suggests that such a view can be an oversimplification, only recently, under Chairman Ben Bernanke, has the FOMC taken steps to codify the policy framework and make it less chair-dependent. The 2012 introduction of the "Statement on Longer-Run Goals and Monetary Policy Strategy" is the clearest example, but there are many others. The increased transparency and accountability gained from the publication of the FOMC's projections forces a more focused discussion of the policy issues at stake in FOMC meetings. And the regular assessments of the risks to financial stability are a step toward better incorporating financial developments into the policy decision process. A key goal of a regular framework review of the type outlined in this paper is to continue the progression toward a more stable framework.

Third, the FOMC's large and diverse composition should in principle provide for a better representation of different viewpoints and a more continuous stress-testing of the framework in place. Although there is truth to this notion, the observation made just above about the importance of the Fed chair in the decisionmaking process also makes it clear that "the FOMC is not a simple democracy, but a consensus-driven organization, with the agenda set by the chair" (Bernanke 2016, 6). This approach to decisionmaking has benefits, but it might well be improved by devising processes to ensure that the status quo is regularly challenged and that necessary changes are adopted in a timely fashion. Again, a regular conference would help serve this function.

In sum, we view a formal framework review as a natural step following those already undertaken to strengthen the Federal Reserve as an institution. Though good policy will always benefit from a good chair, it will also benefit from a resilient framework. Undertaking a regular assessment of the framework that solicits input from varied sources increases accountability and transparency. It also helps to ensure that the framework in place is followed if it remains appropriate, or is changed if merited by economic circumstances or a new understanding. Thus, a regular formal framework review also improves the Fed's accountability, because a regular review 
forces policymakers to better articulate to both the markets and the public at large the rationale for their actions in the context of the framework.

\section{A Suggested Approach for How the Federal Reserve Should Regularly Evaluate the Monetary Policy Framework}

Currently, the Federal Reserve reviews the framework document once a year. At issue is the depth at which it reassesses the document, the openness of the process, and the inputs from which it draws in reviewing. Instituting a less frequent and more thorough process for evaluating the Fed's monetary policy framework, such as that used by the Bank of Canada, sounds straightforward. But in practice, such a process would require decisions on a number of key features of the review. Here, we briefly outline the trade-offs involved with each of the key features, and we recommend one approach to the review process that we believe nicely balances these trade-offs.

\section{III.A. When Should a Review Be Conducted?}

A key factor for deciding when to conduct a review is whether the review's timing should be regular or state-dependent. Ideally, a central bank should be able to make effective changes to its operating framework whenever the need arises. The history recounted in section II suggests that the state of the economy has not always provided sufficient inducement to trigger a framework change. Section II implicitly provides possible guidelines for conditions that could prompt a state-dependent reevaluation:

-A significant deterioration in economic performance that is not readily linked to nonmonetary policy factors, perhaps along the lines of the loss function estimates (squared deviations of inflation from the target and of unemployment from the estimate of the natural rate) presented in figure 1;

-A significant change in the behavior of long-run inflation expectations, and other financial market signals that could imply a loss of efficacy and credibility, for example, along the lines of the results presented in figure 11;

-Or, on a brighter note, compelling evidence from new empirical research in the field that a superior framework exists.

In practice, such indicators and others are routinely examined by the Federal Reserve System's staff. The circumstantial evidence over the Federal Reserve's 105-year history, a portion of which has been examined in the previous section, suggests that changes to the framework have often occurred too slowly at key junctures, most notably during the Great Depression, when the persistent adherence to the gold standard 
critically constrained the Fed's ability to respond to the crisis. Another widely studied example is the 1970 s, when it took more than a decade to successfully address the significant rise in inflation. Given the nonsystematic way in which framework changes have occurred historically, and the mixed history of the timeliness and effectiveness of such changes, we suggest that the FOMC regularly reassess key elements of its framework at a fixed interval, perhaps more formally than the current annual signoff on the "Statement on Longer-Run Goals and Monetary Policy Strategy."

A choice to use a fixed frequency should not, however, be overly rigid. It would be foolish to assume that policymakers can anticipate all the circumstances that might require a change in the framework. Thus, even within a regular frequency review, it might be wise to allow for an escape clause that makes it possible to reassess the situation off the regular schedule.

\section{III.B. Who Sets the Agenda, and Who Provides Input for the Review?}

If a formal review process is undertaken, there are several options for how to structure such a review, most notably who sets the agenda and who participates in the review discussion. These decisions can be more important than it might seem. On one hand, outside political influence in setting the review's agenda could be viewed as eroding the Fed's independence. On the other hand, including outside voices in the review discussion (and making the discussion public) could go a long way toward building public accountability for the Fed's framework decisions.

Because the goal is to use the review as an input into the FOMC's decisions about its framework, we argue that agenda setting should be done primarily by the FOMC, whose members would be required to vote on changes, so there will be FOMC support for any changes that are considered. ${ }^{25}$ Moreover, the FOMC members should know more than anyone else about the key issues with which they have been grappling. The Federal Reserve staff is constantly reassessing the framework; as a result, over the course of time there should be a fairly large inventory of topics from which the FOMC can choose.

Although we suggest that the FOMC and Federal Reserve staff should have primary responsibility for setting the review agenda, one cannot rule out the fact that consensus-building pressures at the FOMC might lead it to overlook dissenting views. To ensure that dissenting views are presented,

25. Any changes to the existing framework would likely be voted on at the following January organizational meeting, when the current framework is approved and other FOMC organizational changes occur. 
it may be helpful to also have non-Fed economists and academics suggest possible topics for discussion at the review. Of course, the FOMC would ultimately decide which topics will be considered.

Although we argue that the FOMC should have primary responsibility for setting the agenda, it seems important for the review itself to include participants with many viewpoints, both internal and external. The details of how to include those with diverse viewpoints could vary. At one end of the spectrum, the review process could be only internal. In this case, the process could still draw on outside expertise, perhaps by surveying relevant research, but possibly also by soliciting external analyses. With respect to the meeting's outcomes, the FOMC would choose how much to disclose and when. At the other end of the spectrum, the analysis supporting the framework review could come solely from external contributors. Such a process might be akin to the processes at some central banks that have engaged an expert panel to provide an independent review of their monetary policy performance in recent years. ${ }^{26} \mathrm{~A}$ key drawback of this option is that external reviewers might be unaware of all the internal work done by Fed staff to evaluate the framework. And one could argue that external evaluations have already taken place to some extent, as reflected in the volume of academic research and conferences devoted to this topic. Thus, on balance, we would argue for a synthesis of these two approaches, incorporating both internal and external inputs into the review.

\section{III.C. What Should Be the Content of a Review?}

One feature that should be common to all reviews is an evaluation of the current framework relative to agreed-upon criteria—for example, estimates of economic loss in recent years from a variety of loss functions, deviations from estimated policy rules, comparisons with optimal policy exercises, and deviations between SEP and market expectations (adjusted for other substantive and methodological differences). These elements of the review should provide a starting point for a discussion about potential changes to the framework. Much of this assessment could be compiled by the staff, but it might be augmented by conference participants' independent performance

26. Most often, these external reviews focus on monetary policy performance broadly defined, rather than on more specific aspects of the policy framework. Examples include the Norges Bank's "Norges Bank Watch," an annual report written by an independent committee of economists to evaluate the bank's monetary policy performance; Ingimundur Fridriksson's 2010 report on the Norges Bank's monetary policy process; the 2000 "Independent Review of the Operation of Monetary Policy," for the Reserve Bank of New Zealand; and a 2010 review of the Reserve Bank of Zimbabwe's monetary policy. 
assessments. Candidates for altering the framework would then be considered, drawing on analyses from both staff and external participants.

The issues related to the elements of the framework outlined in section I are all potential candidates for a review, although as suggested above, we would likely shy away from issues that require alterations to the Federal Reserve Act. In section IV, we describe two challenges facing the current monetary policy framework that could be the subjects of a review. Needless to say, there are other issues worth considering. The historical review of framework changes in section II highlighted shifts in the conduct of monetary policy that were arguably related in part to changing views about the appropriate loss function to minimize. In the current circumstances, a discussion about the symmetry of losses related to unemployment-apart from inflationary consequences, does low unemployment imply losses as large as high unemployment? - could be an ideal focus for a framework review. Changes in economic structure and their influence on the conduct of monetary policy would also be candidates for discussion.

\section{III.D. Who Decides If the Framework Needs to Change?}

The element of the review process focusing on the question of who decides if the framework needs to change should be less controversial. The recommendations that emerge from the review will depend on who sets its agenda and how it is structured. Whether the review is internal, external, or a hybrid of the two will affect who provides the recommendations about potential framework changes. But in the final analysis, only the FOMC has the responsibility for making decisions about the framework, because the FOMC is the one body that is accountable to Congress and the public for monetary policy performance.

\section{III.E. A Proposal for a Framework Review}

A framework review could comprise a number of possible combinations along the dimensions we have described here. One candidate would be a purely internal review, an augmentation of the internal processes already in place. As suggested above, Federal Reserve staff members and FOMC members already devote considerable effort to evaluating the policy framework. But in our view, the internal processes suffer from shortcomings: The time allotted for discussion of the review of the annual framework document has been modest; the scope of questions discussed is normally relatively narrow; and to date, an alternative framework has not been discussed in depth, including a motion with an up-or-down vote on moving in a new direction. Given the historical record, it can be argued that changes 
in the framework, when they have occurred, have not always been timely, and have often been heavily dependent on the chair's leadership. Thus, if one were to choose an internal process, it would be valuable to set aside significant time for the FOMC to discuss recent performance, to identify shortcomings in the framework and its implementation, and to consider changes to the framework that might address any shortcomings identified.

Although the point of a framework review is indeed to augment the FOMC's internal decisionmaking process, it is not clear that keeping the process entirely internal would achieve the desired results. After all, the FOMC has had the option to use its internal processes to alter its framework since its inception. But the historical record outlined in section II suggests that delays and/or ineffective changes to the monetary policy framework were in part due to issues with the FOMC's internal decisionmaking processes. The literature on monetary policy decisionmaking by committee is growing, but still small. ${ }^{27}$ And the extent to which the vast literature on group behavior from social psychology can be readily applied to a committee such as the FOMC is not clear. Nevertheless, one cannot rule out the reality that a committee such as the FOMC may at times be subject to some of the same issues pertaining to performance, coordination, and polarization as those highlighted in the social psychology literature. Broadly speaking, this literature notes that accountability, transparency, and outside examination of the group decisionmaking process are potential ways of mitigating pitfalls associated with group behavior (Sibert 2006).

For these reasons, our preferred approach to a framework review is one that provides roles for the FOMC, for the Federal Reserve staff, and for outside specialists. An open, FOMC-designed evaluation with both internal and external input would increase transparency and accountability, and would broaden perspectives without ignoring the work done internally in the Federal Reserve System. There are issues to consider when opening up the review process, most notably the risk of politicizing the framework review. But such concerns may be mitigated by a review that employs evidence-based argumentation, an important tool to falsify claims driven only by political motives. And it is important to note that an opaque, internal process also has political risks. Making important changes in the monetary policy framework without clearly explaining the process and rationale to the public invites political backlash.

27. Notable contributions are the papers by Blinder and Morgan (2005), Gerlach-Kristen (2004), Riboni and Ruge-Murcia (2010), and Sibert (2006). 
Specifically, we envision a review that occurs mostly at regular frequency. The Bank of Canada's five-year horizon seems a reasonable starting point. A potential option is to adapt this timing to take account of the term of the Federal Reserve chair-allowing for one framework reevaluation for each Fed chair's four-year term. As noted above, we favor the inclusion of an escape clause that allows for an off-schedule reassessment when necessary.

The FOMC should take the lead in setting the agenda, although external input could also be taken into consideration. At the very least, the review should include supporting work by staff explaining the issues and why they were selected. Once the agenda is set, a call for papers on the selected topics would allow interested researchers from academia, other central banks, think tanks, and the private sector to submit their ideas for consideration. Again, the FOMC would take primary responsibility for selecting contributions from among those submitted, perhaps in consultation with external experts. As discussed earlier, the review should include an evaluation of the current framework, which could include both staff-generated and external evaluations of monetary policy performance. The results of the research presented at the conference could be summarized by staff, detailing the findings and what they may imply for framework changes. With the results of this public conference, as well as additional internal work, the FOMC would be well positioned to take formal action on changes it judges to be appropriate.

\section{III.F. The Potential Costs of a Regular Review}

Although we believe our recommendation could modestly improve the Federal Reserve's performance over time, it is wise to consider the potential costs of undertaking such a review. In particular, the Fed should consider the effect that such a process might have on expectations and credibility. Just the existence of such a process might imply to markets that, say, the inflation goal was somewhat more subject to change than it is at present, which might in turn increase the uncertainty about longrun expectations of inflation. The consideration of a specific change in the lead-up to a formal evaluation, if it became public, could similarly increase uncertainty about the Fed's actions in coming years. Suppose, for example, that it became known that, like the Bank of Canada earlier, the FOMC was considering the merits of price-level targeting. Knowledge of this fact should shift some probability weight toward its adoption, and could imply a different trajectory for the funds rate and for inflation over the medium horizon. 
It is not obvious how to mitigate such effects, apart from clear communication about the scope of the review and a gradual buildup of experience with routine framework evaluations. But it is important to recognize that such effects may be at play, and to work to minimize their impact on economic outcomes. It is also important to note that framework changes may be perceived as improvements, and thus help reduce any economic stress-just as the cost of unemployment fluctuations around the natural rate declined when inflation expectations became well anchored.

\section{III.G. How a Formal Review Differs from the Current Process}

As noted above, the staff members of the Federal Reserve System are continuously evaluating elements of the framework. How would the proposed review differ from the ongoing process? There are a number of dimensions in which this framework evaluation would deviate from the ongoing internal process. First, from the FOMC's perspective, the current annual process is more concerned with instituting minor changes than with introducing a major evolution in how the FOMC conducts monetary policy. The process that we are advocating would require a more significant amount of FOMC time to focus on the performance of the current and prospective framework.

And second, the current process does not typically include a performance evaluation of the current framework, in particular: (1) Is the current framework showing signs of stress, or is it expected to in the near future? (2) Has the FOMC deviated significantly from the current framework; and if so, for what reason? (3) Has the FOMC deviated significantly from its "normal" behavior (that is, its estimated policy rule); and if so, for what reason? (4) Have economic losses been larger than usual in recent history? Are some of these losses attributable to monetary policy?

The evaluation would entertain much more input from outsiders. It may not be that outsiders possess unique knowledge about how to improve the framework, but they would bring somewhat different perspectives, and they could reduce any tendency for institutional inertia or group think.

\section{Is Now a Time When We Should Be Rethinking the Monetary Policy Framework?}

Could the current framework be improved? For example, is it at risk of failure when the next downturn occurs? Is there a recognition among current FOMC members that a change should be considered now, perhaps consistent with other times when regimes were changed? The past 
10 years have been marked by a record-sized recession and a financial crisis, the use of alternative tools to reduce the effects of the disruption, and a disappointingly long recovery back to full employment, despite the efforts undertaken during the crisis and in its aftermath. It would be difficult to say that economic performance during the recovery-specifically, the rate at which we reattained full employment-was completely satisfactory. Hence, the monetary policy framework is far from perfected; for a variety of reasons, more needs to be done. Despite the very significant changes over the past decade, the changes to date in its framework document, as detailed above, have been relatively minor. This may be one reason for having a more regularized schedule to discuss framework changes.

It is relevant to note that the two largest episodes of subpar economic performance in the Fed's postwar history have been the Great Inflation of the 1970s and the Great Recession and recovery that began at the end of 2007. In both these cases, one key failing has arguably been the fact that the Fed did not adequately address an emerging problem: whether or how to offset the rising inflation and inflation expectations in the first case, and how to overcome the lack of potent tools to offset recession in a lowinflation, low-real-rate environment in the second case.

In an important sense, these observations provide the strongest motivation for our recommendation for a regular review of the performance of the monetary policy framework. The economic environment is constantly changing, as shown by the two examples given above, when the economy was buffeted by large supply shocks and a declining real rate of interest. The framework must be flexible enough to adapt not only quickly but also effectively. The hope is that a regular review would ensure that the Fed would be ready to make the correct adjustments as soon as possible when they are required.

Here, we consider two high-level challenges currently facing the Fed's monetary policy framework, both of which might be viewed as requiring a change in framework: the potentially increased likelihood of protracted periods at the effective lower bound on interest rates; and the limited ability to stabilize the economy, including a chronic pattern of significantly overshooting full employment - a risk to which nonzero probability attaches in this cycle.

\section{IV.A. The Effective Lower Bound on Interest Rates}

We have been in a low-inflation regime for the better part of two decades. More recently, we have appeared to be in a regime of low real interest rates. These two imply that equilibrium nominal interest rates will, for some time, 
be quite low by historical standards. ${ }^{28}$ This in turn implies that the amount of policy buffer for conventional, short-term interest rate policy-the amount by which the central bank can lower its policy rate in response to an economic downturn - will likely be limited for some time. Thus, one motivation for considering alternative policy frameworks might be a desire to find one that would provide the central bank with a larger policy buffer.

During the Great Recession, we also learned about the efficacy of some key alternative monetary policy instruments. Most notably, the Fed's forays into quantitative easing $(\mathrm{QE})$ and forward guidance provided an opportunity for researchers to estimate the effects of such policies on longer-term interest rates, on other asset prices, on inflation expectations, and on real economic outcomes (for example, Christensen and Rudebusch 2012; Gagnon and others 2011; D'Amico and King 2013; Hamilton and Wu 2012; and Swanson 2017). These findings bear on the confidence with which the Fed might use such tools in the future, which should in turn influence its comfort with a reduced policy buffer for its conventional instrument. If one accepts the median estimates of QE and forward guidance efficacy, and if one takes into account the difficulty experienced in returning the economy to full employment and target inflation following the Great Recession, one cannot assume that the current framework for monetary policy will necessarily provide enough potency to satisfactorily offset a modest to large-sized economic downturn, even combining the effects of conventional and unconventional policies. Thus, the prospect of a continued low-inflation, low-real-rate environment might well prompt consideration of monetary policy framework alternatives.

\section{IV.B. Stabilizing the Economy Is Easier in Theory Than in Practice}

When thinking about alternative policy frameworks in the form, for example, of adopting a price-level target, it is important to consider the record of monetary policy in stabilizing the economy. The top panel of figure 14 shows the four-quarter change in the unemployment rate, with recession shading, from 1949 to the present. The recurrent feature here is that whenever the unemployment rate increases by more than 0.5 percentage point, the economy always falls into a recession. The figure's bottom panel displays the unemployment rate gap over the same period. Whether using the latestvintage estimates of the natural rate (the unemployment gap line) or realtime estimates (the Greenbook-based unemployment gap line), the figure

28. Kiley and Roberts (2017) assess the probability of becoming stuck at the effective lower bound from the perspective of two large econometric models. 
Figure 14. The Record of Monetary Policy in Stabilizing the Economy, 1949:Q1-2018:Q3

\section{Four-quarter change in the unemployment rate}

Percent

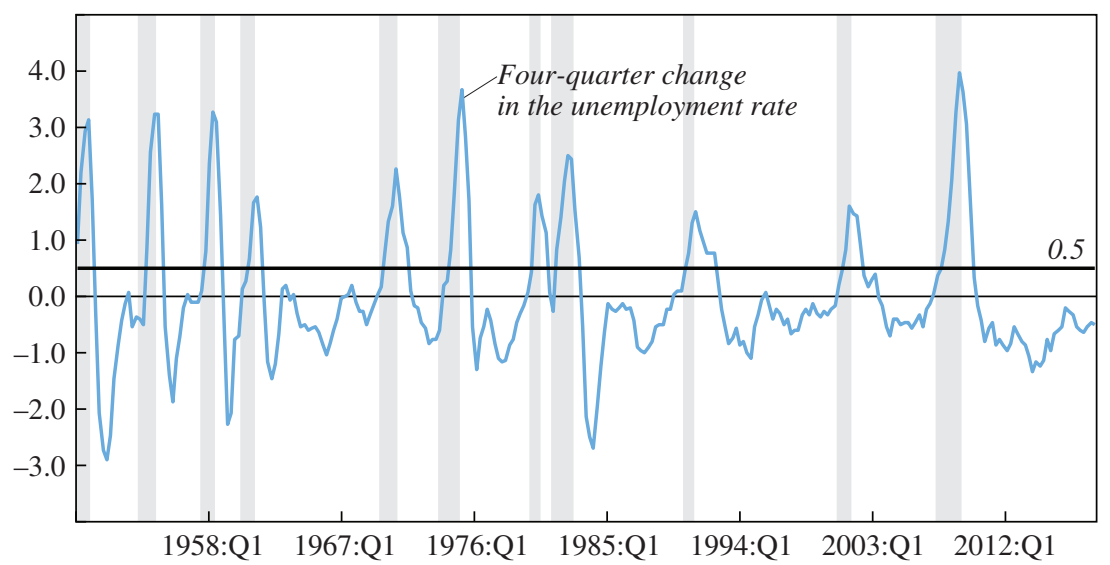

Unemployment gap

Percent

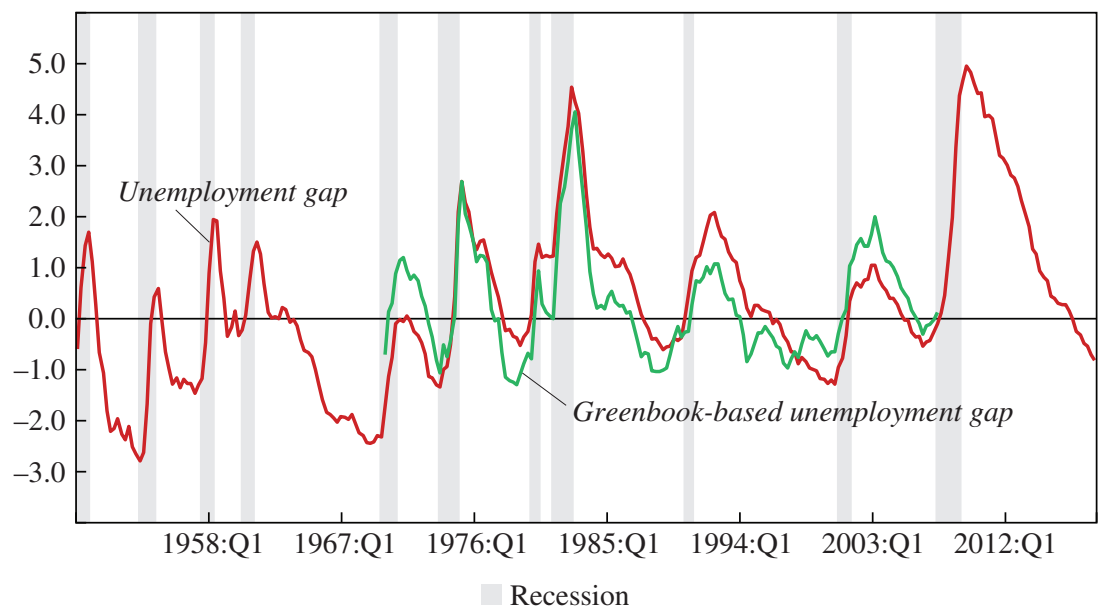

Sources: Bureau of Labor Statistics; Congressional Budget Office; Federal Reserve Board; Haver Analytics; National Bureau of Economic Research. 
shows a pronounced tendency for the unemployment rate to dip significantly and persistently below these estimates of the natural rate at the end of expansions. In every case, this overshooting is followed by a recession. The depth of the overshooting varies, and the magnitude of the ensuing recession varies, but the pattern is nearly perfect for postwar U.S. economic history.

This limited ability to stabilize the economy could be due to events that are beyond the control of monetary policy. In some circumstances, the central bank has intentionally caused a recession, most notably in the case of the Volcker disinflation. It is relevant to note that for the three most recent downturns, staff forecasts as reported in the GB/TB have featured only a mild increase in the unemployment rate, to a level roughly consistent with the real-time estimate of the natural rate. In other words, the recurrent pattern has been one where the tightening of monetary policy has been expected to slow the economy down gently from above capacity to full employment. Ex-post, one might judge that monetary policy exacerbated the unexpected recession, but this is not what the Federal Reserve Board's staff was envisioning ex-ante. The limited ability to predict a recession is well known, and not just a feature of Fed forecasts. Here, we highlight the reality that once the unemployment rate starts to rise by a relatively modest amount, dynamics take hold that tend to push the economy into a recession in ways that standard linear models do not adequately capture.

There could be many reasons for the economy's tendency to overshoot full employment (or, correspondingly, to undershoot the natural rate of unemployment). The Fed (and other forecasters) could be surprised by the vigor of private growth late in the expansion, or by a late-recovery fiscal expansion (as occurred in the late 1960s, during the intensification of the Vietnam War). Still, one never sees an undershoot, by this definition-a landing "above the runway," in which unemployment plateaus above the estimated natural rate before slipping into recession. The pattern is consistent enough that it should prompt thought about the role that monetary policy may play in this recurrent pattern.

The next figures provide some evidence on the Fed's forecasting errors, to see if they might help explain the economy's tendency to systematically overshoot full employment. Figure 15 examines the GB/TB forecasting errors for real GDP growth and unemployment at the four-quarter horizon..$^{29}$

29. Errors are computed using real-time, actual data from the Philadelphia Federal Reserve Bank's database, using the vintage of data eight quarters after the forecast was made. Data for longer-horizon forecasts are not as reliably available for the GB/TB data set, although the pattern for the available six- and eight-quarter-ahead unemployment forecasts is quite similar. 
Figure 15. Greenbook/Tealbook Forecasting Errors at Turning Points in the Unemployment Gap

Errors in unemployment rate at four-quarter horizon

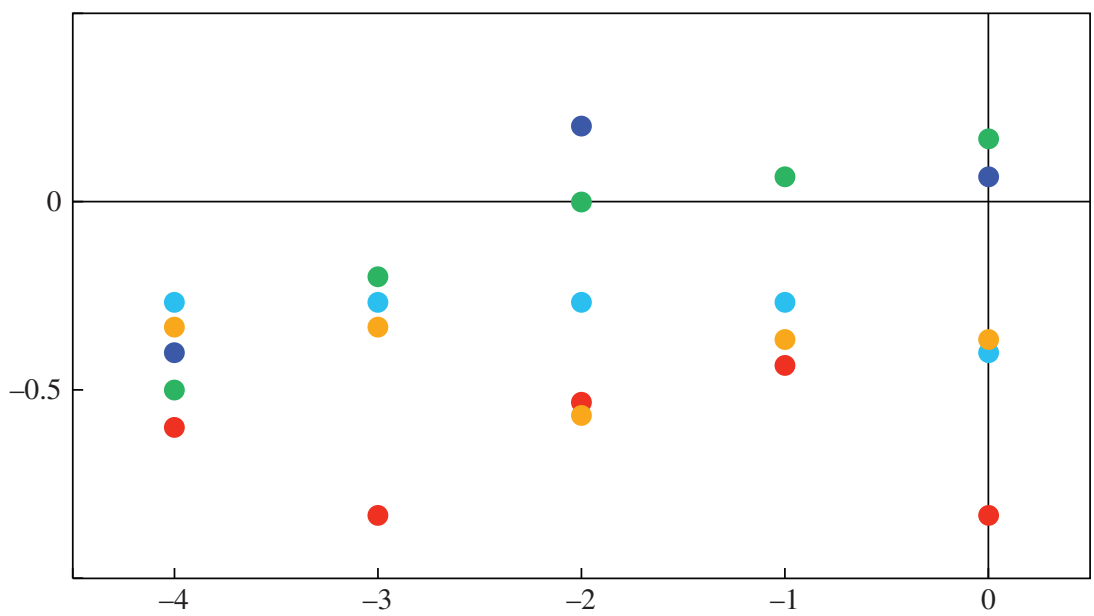

Number of forecasts before sign switch in unemployment gap

Errors in real GDP growth at four-quarter horizon

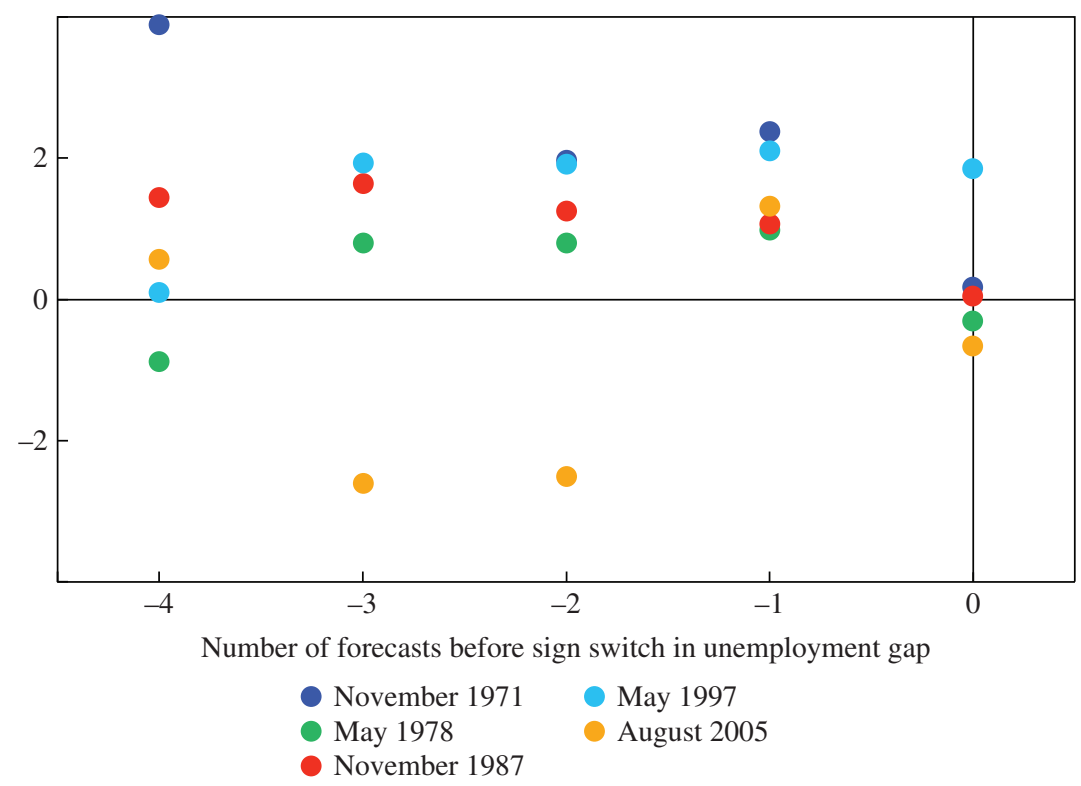

Sources: Bureau of Economic Analysis; Bureau of Labor Statistics; Federal Reserve Board. 
The periods chosen are the forecast dates leading up to the time that the unemployment gap (as displayed above) changes sign from positive to negative. Because the data for the GB/TB are collected beginning in 1965, the first such episode that we can examine is late 1971. After that, there are four other episodes - 1978, 1987, 1997, and 2005-along with a potentially late-breaking episode right now, with the quarterly average unemployment rate at 3.9 percent for 2018:Q2 and the CBO's latest estimate of the natural rate at 4.6 percent. Thus, unemployment has been below the current natural rate estimate since March 2017, or about 17 months_-not a very long time by historical standards.

The top panel of figure 15 shows that at about the time when the unemployment rate begins to undershoot the natural rate (and correspondingly employment overshoots full employment), the GB/TB systematically overpredicts the unemployment rate four quarters ahead (errors are defined as actual minus forecast, so negative numbers indicate an overprediction). The same is true for eight-quarter forecasts, which are not shown. ${ }^{30}$ As indicated in the bottom panel, at the same time, the GB/TB forecasts tend to systematically underpredict real GDP four quarters hence-which is consistent with the kind of Okun's law relationship that appears to be embedded in the GB/TB forecasting process.

Overall, errors forecasted around peaks and troughs could be just a reflection of the fact that the economy is hard to predict, especially at turning points. ${ }^{31}$ But it is also possible that these systematic errors and patterns at key junctures of the business cycle are indicative of more fundamental challenges that make it difficult to fine-tune the economy. Importantly for this paper, this inherent difficulty could be relevant when evaluating possible changes to the framework, such as price-level targeting. In such a regime, the need can arise to keep interest rates low for quite some time to offset the effects of the recession on the price-level gap, and subsequently to restrain the economy for some time, engineering a growth recession that brings inflation back down to target and employment back to full employment. The empirical record of policymakers' ability to engineer a growth recession that nicely lands the economy at full employment without morphing into a full-blown recession is not comforting. Similarly, a soft landing from an overheated economy — whether unexpected or not— to

30. Unfortunately, there are far fewer eight-quarter-ahead than four-quarter-ahead forecasts recorded in the GB/TB historical data set.

31. Recall that an optimal forecast will generally be less variable than the series being forecasted. 
full employment has been a recurrent feature of past forecasts but not of actual outcomes.

\section{IV.C. What Are the Alternatives?}

If this is indeed an appropriate time to be considering the effectiveness of our current framework, what are the alternative approaches we should be considering? Key alternatives should probably include

-Inflation targeting with a different (higher) target rate;

-Adopting an inflation target range rather than a point target. The target range could vary with significant perceived and persistent changes in the equilibrium real rate of interest, per Rosengren (2018);

-Price-level targeting, including (1) conventional price-level targeting; and (2) opportunistic or asymmetric price-level targeting (in the wake of a large recession), thus making up for price-level misses on one side of the notional price path, when the policy rate hits the effective lower bound; ${ }^{32}$

- Nominal GDP targeting, meaning a fixed combination of price-level and real-GDP-gap targeting $;{ }^{33}$

-What should the loss function look like? Is the workhorse function the right one?

Other authors have reviewed the merits of these alternative frameworks, some in more detail than others. Those who have discussed the potential benefits (and costs) of raising the inflation goal to 3 or 4 percent have included Olivier Blanchard, Giovanni Dell'Ariccia, and Paolo Mauro (2010); Olivier Coibion, Yuriy Gorodnichenko, and Johannes Wieland (2012); Laurence Ball (2014); Paul Krugman (2014); John Williams (2016); and Lawrence Summers (2016). Estimates of the potential gains to a higher inflation goal are provided by José Dorich and others (2018) for Canada and by Michael Kiley and John Roberts (2017) for the United States. These authors find that in some circumstances, raising the inflation goal can provide substantial gains to macroeconomic stabilization.

The second option is discussed in a speech by Rosengren (2018), and is motivated by the observation that current estimates of equilibrium real short rates are quite low, implying (with a goal of 2 percent inflation) a low-equilibrium federal funds rate. Thus, the rationale is the same as those

32. See Bernanke (2017).

33. Nominal GDP targeting may be seen as a special case of a dual mandate policy that pursues price-level and output gap targeting, as it imposes weights of one on these two components of the GDP gap. 
for most of the authors cited above. To date, no one has provided a numerical estimate of the benefits of an inflation goal that moves up and down with estimates of the equilibrium real rate.

The bodies of literature on price-level targeting and nominal GDP targeting are voluminous. Aspects of price-level targeting are discussed by Lars Svensson (1999) and by Coibion, Gorodnichenko, and Wieland (2012). Nominal GDP targeting, which implicitly imposes fixed weights of unity on both the real GDP gap and the price-level gap, has the advantage of ignoring the split between real and nominal activity, and thus in a sense automatically adjusts the policy rate when productivity growth (or other determinants of potential GDP growth) slows or speeds up. Robert Hall and N. Gregory Mankiw (1994), Stephen Cecchetti (1996), and Michael Woodford (2012) discuss the relative merits of nominal GDP targeting.

Although it is beyond the scope of this paper, in order to intelligently consider any of the alternatives presented above, we need to consider how we should evaluate the performance of historical and prospective monetary policy frameworks. Relatedly, the Fed (and any evaluation partners) would need to agree on how to assess the counterfactual of whether and/or how much an alternative framework might improve on the current one.

\section{IV.D. Limits to the Alternative Monetary Policy Strategies}

Most of the solutions mentioned above involve either temporary or permanent increases in the inflation goal. However, one must be realistic about how much comfort one should take in an indefinite increase of, say, 1 percentage point in the inflation goal, or a temporary increase of 2 percentage points in the goal. Starting from a steady state with a commensurately higher nominal interest rate would afford more latitude to lower interest rates-sometimes referred to as the amount of policy cushionand would no doubt decrease the severity of a recession. But one must be realistic about the amount of relief such a framework would offer. Some of the studies cited above provide evidence bearing on the benefits of additional policy cushion (Kiley and Roberts 2017; Dorich and others 2018). But to simplify—using estimates from FRB/US, vector autoregressions, and the Federal Reserve Bank of Boston's econometric models-every additional percentage point of federal funds rate decrease would yield about 1 percentage point more in real output, and an unemployment rate that is 0.5 percentage point lower. Thus, a regime with a 4 percent inflation goal would offset roughly 1 more percentage point of unemployment than 
would a 2 percent regime. Though helpful, one should not expect such a framework to provide a complete solution to the types of monetary policy constraints faced, for example, during the Great Recession. ${ }^{34}$

In addition, the apparently shallow slope of the Phillips curve makes the implementation of these policies more complicated. First, moving the economy to a significantly higher inflation rate today would entail a rather protracted period of subnatural rate unemployment. Second and related, on an ongoing basis, recessions that lowered inflation would similarly require protracted periods of low interest rates that, working through the Phillips curve, would move inflation back up to target. These periods of "low for long" would become a regular feature of macroeconomic policy under all these policies, and likely entails some risk of inducing either financial or macroeconomic instability.

The implication of these observations is that we should probably not rely on monetary policy alone, even with the best-designed framework, to take sole responsibility for economic stabilization. There are practical limits on the amount of stimulus that monetary policy could provide in the face of significant economic downturns. This observation implies that one should also consider whether there is an important role for fiscal policy in managing short-run fluctuations. And this of course is a topic for another paper.

\section{Conclusions}

We review some facts about monetary policy frameworks. First, they have changed quite a bit over time, with a frequency that is measured in years, but not decades. Second, they have changed for a variety of reasons. In some cases, such as the appointment of a new Fed chair in 1979, it was clear that economic performance had deteriorated, and a change was required. ${ }^{35}$ In others, the economics profession's understanding of monetary policy frameworks had evolved, and the Fed (often gradually) adapted

34. The same logic applies to the use of balance sheet policies ("quantitative easing" or "large-scale asset purchases" in Fed parlance) to stimulate the economy. The effects of these policies on interest rates to date have been of the same order of magnitude, and thus cannot be expected to offer more stimulus than policies that increase the amount by which short rates can be reduced.

35. One can of course debate whether the 1979 changes constitute a change in framework, or the correction of a misperception regarding the inflation/unemployment trade-off, or a recognition that discretionary deviations from the extant framework had been detrimental, and required a forceful return to the same framework. For the purposes of this paper, we take this to be a change in monetary policy framework. 
to this change, as with the adoption of an explicit numerical inflation objective. In still others, key aspects of economic structure necessitated a change in framework, as in the failure of monetary aggregates to provide reliable indications of nominal GDP growth or inflation. Third, it seems best to characterize most changes in the framework as evolutions, rather than overnight revolutions. Recognition of framework deficiencies, recognition of key changes in economic structure, improvements in the profession's understanding of monetary economics-all these take time, and adoption normally lags recognition. Fourth, the distinction between a change in framework and a discretionary departure from a perfectly sound framework is subtle, but perhaps important. It matters because in some episodes, it may not have been the monetary policy framework but the lack of adherence to that framework that caused problems, and that necessitated a change in monetary policy implementation. Whether this change constituted the adoption of a new framework or better adherence to an old framework remains an open question.

Given this characterization of monetary policy frameworks, we believe the process that ensures adherence to a framework as well as the process for making needed changes to the framework can be improved. In particular, it is important that the Fed should consider a regular assessment of its monetary policy framework at a fixed interval and that this assessment provide a transparent evaluation of the current framework and how it could be improved or possibly changed. We hope that such a review processin part, with the aid of outside contributors-would help the Fed more consistently adhere to its framework when it can continue to work well, and to make timely changes when it cannot. Although changes have regularly been made to the framework, an improved process would institutionalize the process of change, making the Fed less reliant on extraordinary leadership. As a transparent process, it would also help to hold the Fed accountable for adhering to the framework it announces, and to provide public and transparent justifications for changes to its framework. One can overstate the likely impact of such a process, but our judgment is that, over the long span of time, it could well help improve the economic outcomes delivered by the U.S. central bank.

\section{Appendix}

In this appendix, we provide information about data and estimation methods for equations 1,3 , and 4 reported in the text. We start with the inflation forecast equations, which we rewrite here for ease of exposition: 


$$
E_{t} \pi_{t+i}=\beta_{0, t}+\beta_{1, t} E_{t} \pi_{t+i-1}^{4}+\beta_{2, t} E_{t} u_{t+i-1}+v_{i, t}, \quad i=1,2,3 .
$$

In this system of equations, $\pi_{t+i}$ denotes the annualized rate of inflation in quarter $t+i, \pi_{t+i-1}^{4}$ is the average of inflation prevailing over the four quarters from $t+i-1$ to $t+i-4$, and $u_{t+i-1}$ is the level of the unemployment rate at $t+i-1$. The operator $E_{t}$ denotes a forecast made in quarter $t$. We consider forecasts of inflation one, two, and three quarters out, as indexed by $i$. We exclude the "nowcast" $E_{t} \pi_{t}$, because such a forecast is likely to be influenced by short-term factors that would not be adequately captured by equation 1. At each of the three forecasted horizons, the relationship is augmented by an error term, $v_{i, t}$. These errors are assumed to be persistent. In particular, we posit that $v_{1, t}$ evolves as an $M A(4)$ process. In each quarter $t$, we then have that $v_{2, t}=E_{t} v_{1, t+1}+\varepsilon_{2, t}$, and $v_{3, t}=E_{t} v_{1, t+2}+\varepsilon_{3, t}$, where the innovations $\varepsilon_{2, t}$ and $\varepsilon_{3, t}$ are such that $\operatorname{Cov}\left(\varepsilon_{2, t}, \varepsilon_{2, t-j}\right)=\operatorname{Cov}\left(\varepsilon_{3, t}, \varepsilon_{3, t-j}\right)=0$ for any $j \geq 1$, but we allow $\operatorname{Cov}\left(\varepsilon_{2, t}, \varepsilon_{3, t}\right)$ to be different from zero.

The $\beta$ coefficients in equation 1 are assumed to evolve as random walks, with uncorrelated innovations across coefficients. The coefficients remain the same at the three forecast horizons at which the relationship in equation 1 is estimated over, as only the timing of the variables is changing in accordance with $i$. This multiple-horizon aspect of the forecasts is especially useful for our purposes in that, under the plausible assumption that the same model is being used to forecast inflation at different horizons, it increases the degrees of freedom at the estimation stage, possibly allowing for a better identification of the coefficients of interest. The specification we use to model the inflation forecasts is admittedly simple, but it captures a fraction of the variation in the inflation forecasts, which, absent time variation in the estimated $\beta$ coefficients, is already above 90 percent. The behavior of the inflation forecasts in equation 1 at the three different horizons is estimated jointly via maximum likelihood using the Kalman filter, over the period 1966:Q4-2017:Q4.

The Federal Reserve Board staff forecasts reported in the GB/TB are produced at every scheduled FOMC meeting, and the meetings have occurred at varying frequency but always more than once per quarter. To avoid estimation issues associated with uneven frequencies, we only consider one GB/TB per quarter, usually the one that coincides with the quarter's middle month. When this is not possible, we consider the last GB/TB forecast made in any given quarter. Given that the staff's forecasts are made public with a five-year lag, for the period from 2013 to the present we use for our analysis the FOMC's economic projections. Specifically, for each SEP forecast that we consider, we take the middle point of the 
published "central tendency" range. Unlike the staff's forecasts, where the outlook is described at a quarterly frequency, the FOMC forecasts are less granular and follow a yearly frequency. We therefore interpolate these yearly forecasts to convert them to quarterly frequency. Such a procedure obviously injects additional noise into the exercise, but our findings are not affected qualitatively by the use of the publicly available FOMC projections for the most recent period. The inflation forecast is for the GDP deflator until 1985:Q4, for core CPI from 1986:Q1 to 2005:Q4, and for the core personal consumption expenditures deflator from 2006:Q1 to 2017:Q4. Given the forecasted horizons that we consider, the variable $E_{t} \pi_{t+i-1}^{4}$ includes a mix of forecasted and realized inflation. Whenever actual inflation is involved, we consider real-time realizations.

As concerns the estimated policy rule, it takes the form

$$
f f_{t}=\gamma_{0, t}+\gamma_{f f t, t} f f_{t-1}+\gamma_{\pi, t} E_{t} \pi_{t+3}+\gamma_{u, t} E_{t} u_{t+3}+v_{t} .
$$

The only variable we have not already defined is the federal funds rate, $f f$, which is given by the average value prevailing in the week after the FOMC meeting. The frequency is quarterly, with the same GB/TB selection criterion for the forecast variables $E_{t} \pi_{t+3}$ and $E_{t} u_{t+3}$ described above in the context of inflation equation 1 . The error term, $v_{t}$, is assumed to follow an $M A(1)$ process. We allow for the variance in the error to exhibit breaks in 1979:Q4, 1986:Q1, and 1997:Q1. Accounting for the possible presence of heteroscedasticity in $v_{t}$ is potentially important in order to correctly apportion time variation to the estimated coefficients. We posit that the $\gamma$ coefficients evolve as random walks, with uncorrelated innovations across coefficients. The policy rule is estimated via maximum likelihood using the Kalman filter, over the period 1966:Q4-2017:Q4. We do not consider the post-2008 period because of the binding floor on the federal funds rate, whereas the starting date is dictated by the availability of the $\mathrm{GB} / \mathrm{TB}$ forecast at the chosen horizon. For the exercise reported in figure 10, which uses forecasts of inflation and the unemployment rate from 2015:Q4 to the present, we consider the SEP projections as described above. In the context of univariate equation 3, maximum-likelihood estimates via the Kalman filter of the variance of the innovations in the random-walk processes underlying the time-varying coefficients $\gamma$ will be biased toward zero. We use the median unbiased estimation procedure given by James Stock and Mark Watson (1998) to first estimate the variance in these innovations. Given such estimates, we then apply the Kalman filter to estimate the remaining parameters in equation 3 . 
Finally, in the daily-frequency regression

$$
\begin{aligned}
\Delta i_{t}^{F, j}= & \alpha_{0}+\alpha_{1} \Delta i_{t} \mathrm{~d}_{t}(\text { release day }=1) \\
& +\alpha_{2} \Delta i_{t}\left(1-\mathrm{d}_{t}(\text { release day }=1)\right)+\varepsilon_{t},
\end{aligned}
$$

we use data on U.S. Treasury forward rates $i_{t}^{F j}$ maintained by the Federal Reserve Board. These data are computed from U.S. Treasury yields, and the details of the computations can be found in the paper by Gürkaynak, Sack, and Jonathan Wright (2007). The dummy variable $\mathrm{d}_{t}$ takes the value of 1 on days when there is a CPI release or a PPI release, and a value of zero on the other days. The equation is estimated via ordinary least squares for each of the forward rates with maturity $j$ going from 2 to 15 years. The estimates reported in figure 11 over the two subsamples that we consider, 1970-96 and 1997-2007, feature heteroscedasticity-consistent confidence bands. Estimation results in the earlier sample are sensitive to outliers, and for this reason we have excluded from the estimation observations featuring a daily change in the three-month Treasury bill rate $\Delta i_{t}$ in excess of 50 basis points in absolute terms. Once outliers have been excluded, it is of interest to note that considering the 1970s, 1980s, and early 1990s separately produces estimates that are qualitatively similar to the ones reported for the entire 1970-96 period.

ACKNOWLEDGMENTS We thank our editors, Janice Eberly and James Stock, and our discussants, Jean Boivin and Stanley Fischer, for helpful comments. David Brown, Emily Freeman, and Peggy Gilligan provided excellent research assistance. 


\section{References}

Ball, Laurence M. 2014. "The Case for a Long-Run Inflation Target of Four Percent." International Monetary Fund Working Paper 14-92. Washington: International Monetary Fund.

Bernanke, Ben S. 2006. "Monetary Aggregates and Monetary Policy at the Federal Reserve: A Historical Perspective.” Paper presented at Fourth European Central Bank Central Banking Conference, Frankfurt, November 10.

- 2016. "Federal Reserve Economic Projections: What Are they Good For?" Brookings blog, November 28. https://www.brookings.edu/blog/ben-bernanke/ 2016/11/28/federal-reserve-economic-projections/.

2017. "Monetary Policy in a New Era." Paper presented at conference on Rethinking Macroeconomic Policy, Peterson Institute, Washington, October 12-13.

Binder, Sarah A., and Mark Spindel. 2016. "Independence and Accountability: Congress and the Fed in a Polarized Era." Brookings Institution, Center for Effective Public Management. https://www.brookings.edu/wp-content/uploads/ 2016/07/Monetary-politics.pdf.

Blanchard, Olivier J., Giovanni Dell' Ariccia, and Paolo Mauro. 2010. "Rethinking Macroeconomic Policy." Journal of Money, Credit and Banking 42 (supplement, 1, September): 199-215.

Blinder, Alan S. 1998. Central Banking in Theory and Practice. MIT Press.

Blinder, Alan S., and John Morgan. 2005. "Are Two Heads Better Than One? Monetary Policy by Committee." Journal of Money, Credit and Banking 37: 789-811.

Boivin, Jean. 2006. "Has U.S. Monetary Policy Changed? Evidence from Drifting Coefficients and Real-Time Data." Journal of Money, Credit and Banking 38: 1149-74.

Cecchetti, Stephen G. 1996. "Inflation Indicators and Inflation Policy." In NBER Macroeconomics Annual 1995, Volume 10, edited by Ben S. Bernanke and Julio J. Rotemberg. MIT Press.

Christensen, Jens H., and Glenn D. Rudebusch. 2012. "The Response of Interest Rates to U.S. and U.K. Quantitative Easing.” Economic Journal 122, no. 564: F385-F414.

Clarida, Richard, Jordi Galí, and Mark Gertler. 2000. "Monetary Policy Rules and Macroeconomic Stability: Evidence and Some Theory." Quarterly Journal of Economics 115, no. 1: 147-80.

Coibion, Olivier, Yuriy Gorodnichenko, and Johannes Wieland. 2012. "The Optimal Inflation Rate in New Keynesian Models: Should Central Banks Raise Their Inflation Targets in Light of the Zero Lower Bound?" Review of Economic Studies 79, no. 4: 1371-1406.

Conti-Brown, Peter. 2016. The Power and Independence of the Federal Reserve. Princeton University Press. 
D’Amico, Stefania, and Thomas B. King. 2013. "Flow and Stock Effects of Large-Scale Treasury Purchases: Evidence on the Importance of Local Supply." Journal of Financial Economics 108, no. 2: 424-48.

Dorich, José, Nicholas Labelle St-Pierre, Vadym Lepetyuk, and Rhys R. Mendes. 2018. "Could a Higher Inflation Target Enhance Macroeconomic Stability?" BIS Working Paper 720. Bank for International Settlements.

Erceg, Christopher, James Hebden, Michael Kiley, David López-Salido, and Robert Tetlow. 2018. "Some Implications of Uncertainty and Misperception for Monetary Policy." Finance and Economics Discussion Series 2018-059. Washington: Board of Governors of the Federal Reserve System.

Gagnon, Joseph, Matthew Raskin, Julie Remache, and Brian Sack. 2011. "The Financial Market Effects of the Federal Reserve's Large-Scale Asset Purchases." International Journal of Central Banking 7, no. 1: 3-43.

Gerlach-Kristen, Petra. 2004. "Is the MPC's Voting Record Informative about Future U.K. Monetary Policy?" Scandinavian Journal of Economics 106, no. 2: 299-313.

Goodfriend, Marvin, and Robert G. King. 2005. "The Incredible Volcker Disinflation." Journal of Monetary Economics 52, no. 5: 981-1015.

Greenspan, Alan. 2004. "Risk and Uncertainty in Monetary Policy." Remarks at Meetings of American Economic Association, San Diego, January 3. https:// www.federalreserve.gov/boarddocs/speeches/2004/20040103/default.htm.

. 2005. "Reflections on Central Banking." Remarks at symposium sponsored by Federal Reserve Bank of Kansas City, Jackson Hole, Wyo., August 26. https:// www.federalreserve.gov/boarddocs/speeches/2005/20050826/default.htm.

Gürkaynak, Refet S., Brian Sack, and Eric Swanson. 2005. "The Sensitivity of Long-Term Interest Rates to Economic News: Evidence and Implications for Macroeconomic Models." American Economic Review 95, no. 1: 425-36.

Gürkaynak, Refet S., Brian Sack, and Jonathan H. Wright. 2007. "The U.S. Treasury Yield Curve: 1961 to the Present." Journal of Monetary Economics 54, no. 8: 2291-2304.

Hall, Robert E., and N. Gregory Mankiw. 1994. "Nominal Income Targeting." In Monetary Policy, edited by N. Gregory Mankiw. University of Chicago Press.

Hamilton, James D., and Jing Cynthia Wu. 2012. "The Effectiveness of Alternative Monetary Policy Tools in a Zero Lower Bound Environment." Journal of Money, Credit and Banking 44 (supplement 1, February): 3-46.

Iakova, Dora M. 2007. "Flattening of the Phillips Curve: Implications for Monetary Policy." IMF Working Paper 07/76. Washington: International Monetary Fund.

Ireland, Peter N. 2007. "Changes in the Federal Reserve's Inflation Target: Causes and Consequences." Journal of Money, Credit and Banking 39, no. 8: 1851-82.

Kiley, Michael T., and John M. Roberts. 2017. "Monetary Policy in a Low Interest Rate World." Brookings Papers on Economic Activity, Spring, 317-72.

King, Robert G., Yang K. Lu, and Ernesto S. Pastén. 2008. "Managing Expectations." Journal of Money, Credit and Banking 40, no. 8: 1625-66. 
Kozicki, Sharon, and Peter A. Tinsley. 2001. "Shifting Endpoints in the Term Structure of Interest Rates," Journal of Monetary Economics 47, no. 3: 613-52.

Krugman, Paul. 2014. "Inflation Targets Reconsidered." Paper prepared for Forum on Central Banking sponsored by European Central Bank, Sintra, Portugal, May 26.

Meltzer, Allan H. 2002. A History of the Federal Reserve, Volume 1: 1913-1951. University of Chicago Press.

- 2010. A History of the Federal Reserve, Volume 2, Book 1: 1951-1969. University of Chicago Press.

-. 2014. A History of the Federal Reserve, Volume 2, Book 2: 1970-1986. University of Chicago Press.

Murray, John. 2018. "Why the Bank of Canada Sticks with 2 Percent Inflation Target." Paper presented at conference on Rethinking the Fed's 2 Percent Inflation Target, Hutchins Center on Fiscal and Monetary Policy, Brookings Institution, Washington, January 8.

Orphanides, Athanasios. 2003. "Historical Monetary Policy Analysis and the Taylor Rule.” Journal of Monetary Economics 50, no. 5: 983-1022.

Orphanides, Athanasios, and David W. Wilcox. 2002. "The Opportunistic Approach to Disinflation." International Finance 5: 47-71.

Peek, Joe, Eric S. Rosengren, and Geoffrey M. B. Tootell. 2015. "Should U.S. Monetary Policy Have a Ternary Mandate?" Paper presented at Federal Reserve Bank of Boston's Annual Economic Conference, October. https://www.bostonfed. org/macroprudential2015/papers/Rosengren-Peek-Tootell.pdf.

Reis, Ricardo. 2013. “Central Bank Design.” Journal of Economic Perspectives 27, no. 4: 17-44.

Riboni, Alessandro, and Francisco J. Ruge-Murcia. 2010. "Monetary Policy by Committee: Consensus, Chairman Dominance, or Simple Majority?" Quarterly Journal of Economics 125, no. 1: 363-416.

Romer, Christina D., and David H. Romer. 2002. "The Evolution of Economic Understanding and Postwar Stabilization Policy." In Proceedings of the Economic Policy Symposium at Jackson Hole, Federal Reserve Bank of Kansas City, 11-78.

_. 2013. "The Most Dangerous Idea in Federal Reserve History: Monetary Policy Doesn't Matter.” American Economic Review 103, no. 3: 55-60.

Rosengren, Eric S. 2018. "Considering Alternative Monetary Policy Frameworks: An Inflation Range with an Adjustable Inflation Target." Paper presented at Money, Models, and Digital Innovation Conference, Global Interdependence Center, San Diego, January 12.

Rotemberg, Julio J., and Michael Woodford. 1997. "An Optimization-Based Econometric Framework for the Evaluation of Monetary Policy." In NBER Macroeconomic Annual 1997, Volume 12, edited by Ben S. Bernanke and Julio J. Rotemberg. MIT Press.

Sargent, Thomas J. 2001. The Conquest of American Inflation. Princeton University Press. 
Sibert, Anne. 2006. "Central Banking by Committee." International Finance 9: $145-68$.

Stock, James H., and Mark W. Watson, 1998. "Median Unbiased Estimation of Coefficient Variance in a Time-Varying Parameter Model." Journal of the American Statistical Association 93, no. 441: 349-58.

Summers, Lawrence H. 2016. "A Thought-Provoking Essay from Fed President Williams." http://larrysummers.com/2016/08/18/6937.

Svensson, Lars E. O. 1999. "Price-Level Targeting versus Inflation Targeting: A Free Lunch?" Journal of Money, Credit and Banking 31, no. 3, part 1: 277-95.

Swanson, Eric T. 2017. "Measuring the Effects of Federal Reserve Forward Guidance and Asset Purchases." NBER Working Paper 23311. Cambridge, Mass.: National Bureau of Economic Research.

Williams, John C. 2016. "Monetary Policy in a Low R-Star World." FRBSF Economic Letter 2016-23, August 15.

Woodford, Michael. 2002. "Inflation Stabilization and Welfare." Contributions to Macroeconomics 2, no. 1, article 1.

2012. "Methods of Policy Accommodation at the Interest-Rate Lower Bound." In Proceedings of the Economic Policy Symposium at Jackson Hole, Federal Reserve Bank of Kansas City, 185-288. 


\section{Comments and Discussion}

\section{COMMENT BY}

JEAN BOIVIN A full decade after the global financial crisis, there is little agreement about the lessons of the crisis for monetary policy frameworks-let alone any implementation of major changes. The role of financial stability considerations in the setting of monetary policy, I would argue, remains one of the most important unresolved questions. But that is not the only one. The risk of hitting the zero lower bound poses other questions: Should the level of the inflation target be higher? Would price-level targeting —or its close cousin, nominal GDP targeting—be a superior framework for dealing with drawn-out periods of disinflation? That these fundamental questions remain unresolved suggests the potential for significant improvements in the Federal Reserve's monetary policy framework.

How should the Fed ensure that desirable framework changes are implemented in a timely manner? This paper by Jeff Fuhrer, Giovanni Olivei, Eric Rosengren, and Geoffrey Tootell tackles this important question. It argues for a Bank of Canada-inspired five-year formal review of the policy framework. The authors document that the Fed has made periodic framework changes anyway, but they have been ad hoc and delayed. Ensuring timely adoption while also avoiding undesirable changes requires a more systematic review with proper triggers. This would also ensure greater accountability and adherence to the Fed's legally mandated objectives.

Conflict of Interest Disclosure: The author, who is the managing director and global head of research at BlackRock, did not receive financial support from any firm or person for this paper or from any firm or person with a financial or political interest in this paper. No outside party had the right to review this paper before circulation. 
I agree with Fuhrer and his colleagues that a more robust and systematic framework review process is needed. As they make clear, framework changes did occur. But without a formal process in place, the changes were often reactive, responding to problems or emergency situations. Looking ahead, preventing or addressing future crises may require proactive change. As the authors imply, changes with such foresight seem unlikely to happen without a more formal review and assessment process.

Recommending a formal review process may sound reasonable, but such a process creates important challenges that need to be addressed before implementation.

The only challenge that Fuhrer and his colleagues highlight is the communication of framework changes to financial markets. This challenge is overstated: A framework review process does not create greater communication problems than the status quo. Framework changes occurred regularly, the authors argue. Financial markets must contend with these odds whether or not a formal review process exists. One could even argue that a more deliberate review process would also lead to more deliberate communication.

In my view, the elephant in the room is the greater challenge: the political economy of monetary policy. Fuhrer and his colleagues approach the framework review process largely from a technocratic perspective. They appear to assume that the Fed will be firmly in control of the process. The reality would be quite different, I believe. Any meaningful framework change will require democratic legitimacy. Importantly, ignoring the political economy considerations could put the Fed's operational independence at risk. In addition, the necessary political engagement in the process could create more inertia.

I believe the experience of the Bank of Canada - with its five-year inflation targeting renewal-illustrates both the importance of having a formal review process and the significant challenges.

RISKS TO DEMOCRATIC LEGITIMACY OR OPERATIONAL INDEPENDENCE The first key challenge: Many of the framework changes that Fuhrer and his colleagues document, or are being contemplated, require democratic legitimacy-this can only be achieved through government involvement. This includes any changes related to the fundamental objectives of monetary policy or any changes that may have significant distributional consequences. Choosing the appropriate level of inflation is one example. The government should be accountable for establishing the socially desirable level of inflation - a tax with distributional consequences-while taking into account the implications for the efficacy of monetary policy. 
Addressing financial stability concerns also has the potential for important sectoral and distributional implications that would require agreement with the government.

This is why-and it is important to stress this-Canada's inflationtargeting framework and its renewal constitute a joint agreement between the Bank of Canada and the Government of Canada. This is key. The renewal process is first and foremost an exercise in democratic accountability. It provides an occasion to formally evaluate whether the Bank of Canada is meeting its commitments to Canada's citizens. In recent years, there has also been a deliberate objective to make the renewal process more transparent and to engage Canadians more directly. One manifestation of this evolution: The 2021 Inflation-Targeting Renewal Conference had its first webcast in the fall of 2017 (Bank of Canada 2017). This marked a major shift away from what had been an invitation-only, off-the-record event for policymakers and academics.

In contrast, other types of changes should be insulated from the political process. To achieve its mandated objectives, a central bank is responsible for decisions based upon the bank's best understanding of the economy. As this understanding evolves, the central bank needs to have the flexibility to adapt its view on which model best represents the economy at that time. A concrete example mentioned by Fuhrer and his colleagues is the level of the neutral policy rate. This is not something that a central bank chooses or directly influences, but that conceptually plays a role similar to a north star for navigators (albeit on a cloudy night). Whether the neutral rate moves up or down is not a matter of democratic legitimacy. It is something a central bank needs to adapt to. The central bank needs to explain the evolution of the neutral rate to the public and needs to defend why it is adjusting policy in response. Political considerations should not interfere with a central bank's decisions on which models it uses, or its assessment of the economy.

These distinctions are crucial—and more complicated — when it comes to unconventional policies, such as quantitative easing and a negative interest rate policy. Consider two important aspects. First, these issues are mostly operational, for the purpose of ensuring that a central bank has the necessary tool kit to achieve its legally mandated objectives. For this reason, these decisions should not become overly politicized. In this regard, it is worth noting that the Bank of Canada's introduction of a framework for unconventional policy in 2009 occurred outside the fiveyear review process. It was part of the normal monetary policy process. Second, some tools can have direct distributional implications and blur the 
distinction between fiscal and monetary policy. The introduction of such tools should then explicitly involve the government.

One of my main concerns with Fuhrer and his colleagues' proposal is that it fails to draw these important distinctions. Setting a review process without a clear understanding of when and how the government should be involved could be risky. Ignoring the potential societal trade-offs of these policy changes can lead to political backlash. On the flip side, a formal review process can invite greater attention and politicization to what should remain operational aspects of monetary policy, and under the purview of the central bank. A formal review process that does not clarify these boundaries risks undermining both the legitimacy and the operational independence of the Fed.

MORE TIMELY ADOPTION OR INERTIA? According to Fuhrer and his colleagues, an important reason for a formal review process is to ensure periodic and timely adoption of framework changes. This is not obvious to me.

Since Canada's renewal process began in 1991, there have been five renewals-most recently, in October 2016. This process has been effective in providing democratic accountability for the Bank of Canada's policies, and it has also allowed ongoing research on potential improvements to the inflation-targeting framework.

But over the past 25 years, how many actual framework changes have occurred through this process? None. Why? A little detour into the episode leading up to the 2011 inflation-targeting renewal is instructive. There are other instructive episodes, but I happened to have been directly involved in this one.

At the beginning of this review process, the Bank of Canada put two questions on the table: (1) Should it target a lower level of inflation (yes, "lower"!)? And (2) should it instead target a path for the level of prices?

However, the global financial crisis shed a different light on these questions-maybe the question is not whether the level of the inflation target should be lower, but in fact higher. The crisis also prompted a third question: To what extent should monetary policy take account of financial stability considerations?

This new question became the most pressing issue at the time. The 2011 renewal was the first opportunity to reassess the Bank of Canada's policy framework since the financial crisis. We wanted to ensure that we drew the right lessons from the crisis. We also needed to explicitly address the fact that price stability does not guarantee financial or economic stability. Part of the answer to this problem is that the first lines of defense were 
elsewhere: building a resilient financial system, with improved regulations and micro- and macroprudential policies. But at the same time, we realized that these lines of defense could be insufficient. Perhaps monetary policy might have a more direct role to play-particularly if monetary policy itself can contribute to excessive risk-taking?

Did the importance of this question lead to a change in the policy framework? We had an intense debate within the Bank of Canada. One view was that no framework changes were needed because the inflation-targeting regime in Canada already provided the flexibility to respond to financial imbalances by simply allowing the Bank to bring inflation back to target over a longer time horizon. Another view was that a credible framework should specify how this flexibility with the inflation-targeting regime would be used. The Bank had not made completely clear whether it intended to use this flexibility to lean against a buildup of financial imbalances-for example, raising rates higher than was called for by the near-term inflation outlook. If the Bank ever used this flexibility, it might come as a surprise. According to this latter view, such a clarification needed to be explained as a framework change.

This was not a theoretical debate. The linkages between high housing prices and elevated household debt levels in Canada were causes for concern, particularly when policy rates were expected to be low for longer. Would the Bank need to tighten policy with the explicit intent of mitigating these financial stability concerns? Would this be understood by Canadians as consistent with the policy framework? At the time, these were live, actively considered questions about the policy stance and its outlook.

This is how the debate unfolded within the Bank of Canada. However, the joint agreement with the government meant the political implications needed to be considered. No matter how important this was from a public policy perspective, concerns about financial stability were just not a high priority for most Canadians-in fact, it was almost the opposite. Had Canada not just proven the robustness of its financial system during a crisis? Why take the risk of turning a nonissue into an issue? "If it ain't broke, why fix it?" To be clear, this discussion was not about the monetary policy implications-whether the Bank should lean against financial imbalances-but rather whether the potential to "lean against the wind" should be communicated to the public as a framework change or simply a reaffirmation of the status quo.

The point is this: The political economy considerations can create understandable inertia and a bias toward the status quo. I am not a political 
scientist, but I believe this is a manifestation of the literature on "path dependence" in political science-why institutions are sticky and political actors are incentivized to protect the status quo.

In the end, the outcome was somewhere in between. The renewal background document and the joint agreement put greater emphasis than ever before on the role that financial stability should play in monetary policy and how the Bank of Canada might react. But the Bank stopped short of characterizing this as a framework change. The summary statement in the joint agreement characterized the outcome as a reaffirmation of the existing framework:

These lessons reinforce the value of Canada's flexible inflation-targeting framework, including its ability to respond to external shocks and its occasional role in supporting financial stability. (Bank of Canada 2011, 3; emphasis added)

The document also clarified explicitly for the first time that this flexibility could involve leaning against financial imbalances, with a technical box providing a concrete illustration:

Second, through a longer targeting horizon, monetary policy can also promote adjustments to financial excesses or credit crunches. ... On the flip side, a tighter monetary policy that allows inflation to run below target for a longer period than usual could help to counteract pre-emptively excessive leverage and a broader buildup of financial imbalances. (Bank of Canada 2011, 33)

This framework clarification was soon put to work. Between April 2012 and September 2012, the Bank of Canada's four press releases all concluded with this sentence on monetary policy stimulus:

The timing and degree of any such withdrawal will be weighed carefully against domestic and global economic developments. (Carney 2012a)

But then, in October 2012, this was changed to:

The timing and degree of any such withdrawal will be weighed carefully against global and domestic developments, including the evolution of imbalances in the household sector. (Carney 2012b; emphasis added)

For the first time, a policy statement indicated the possibility that the policy setting could be adjusted in response to financial imbalances. But in the October 2015 Monetary Policy Report opening statement, the Bank of Canada made this statement:

Our risk-management approach implied that, in the absence of any additional macroprudential measures, our actions would affect the balance of risks in opposite directions. Lowering interest rates could worsen vulnerabilities related to household debt at the margin, but it would also lessen the chances of the oil 
price shock triggering financial stability risks. In the current context, getting the economy back to full capacity with inflation on target is central to promoting financial stability over the longer term. (Poloz 2015)

Like the previous statements, this acknowledged that financial stability played a role in the setting of monetary policy. But in this case, the Bank of Canada was not making a statement about its ability to lean against rising financial imbalances by tightening policy. It was signaling that it might keep policy easier to avoid worsening financial stability concerns. This is not about any inconsistency with Canada's flexible inflationtargeting framework: When financial vulnerabilities are high, the Bank's inflation-targeting framework allows it to respond in both directions with easier or tighter policy. But the framework provides little guidance as to when one is more appropriate than the other.

This episode shows that the review process allowed the Bank of Canada to clarify that it can lean against financial imbalances. And in some ways, it has already done so. This is important progress. But what principles govern how the Bank will respond in practice to the buildup of imbalances? The policy framework does not yet provide a clear answer. Why is this question not fully resolved? I think part of the explanation is that politically, it is easier to incorporate these considerations through a reaffirmation of the flexibility of the regime-defending the status quo-rather than making the case for a framework change.

CONCLUSION To conclude, I agree with Fuhrer and his colleagues that there is strong case to formalize a regular and systematic review process to consider the Federal Reserve's policy framework. I believe this is needed to guarantee the efficiency of the policy framework and its democratic legitimacy. But this process will inevitably have to involve the government, and this needs to be explicitly acknowledged. The process needs to delineate what type of framework changes should be jointly decided and what operational and implementation flexibility should be insulated from political influence. Otherwise, the process risks undermining the Fed's operational independence and could interfere with the timely adoption of necessary operational improvements.

\section{REFERENCES FOR THE BOIVIN COMMENT}

Bank of Canada. 2011. "Renewal of the Inflation-Control Target." https://www. bankofcanada.ca/wp-content/uploads/2011/11/background_nov11.pdf. 2017. "Monetary Policy Framework Issues: Toward the 2021 InflationTarget Renewal.” Workshop summary. https:/www.bankofcanada.ca/2017/09/ monetary-policy-framework-issues-toward-2021-inflation-target-renewal/. 
Carney, Mark. 2012a. "Opening Statement before the House of Commons Standing Committee on Finance." https://www.bankofcanada.ca/2012/04/ opening-statement-24-april-2012/.

- 2012b. "Opening Statement before the House of Commons Standing Committee on Finance." https://www.bankofcanada.ca/2012/10/openingstatement-30-october-2012/.

Poloz, Stephen S. 2015. "Integrating Financial Stability into Monetary Policy." Paper presented at annual membership meeting of Institute of International Finance. https://www.bis.org/review/r151012a.pdf.

\section{COMMENT BY}

STANLEY FISCHER As its title states, this paper by Jeff Fuhrer, Giovanni Olivei, Eric Rosengren, and Geoffrey Tootell addresses the question of whether the Federal Reserve should regularly evaluate the need to modify the monetary policy framework. That is done in the first part of the paper, consisting of the introduction and the question "How do we define a monetary policy framework?" The second and longer part of the paper starts with a historical review of monetary policy frameworks since the 1960s, and then examines issues relating to the process of regularly evaluating the framework. The paper concludes with another question, asking whether this is a time when we should be rethinking the monetary policy regime.

Let me start by saying that I believe a central bank should have enough analytic and executive capacity to make monetary policy on its regular schedule, and at the same time should be reevaluating its monetary policy framework and considering potential changes. In this context, I find the concepts of "regularly evaluating" and "monetary policy framework" as set out in the paper not entirely clear; my view is that an institution of the importance of a central bank - and the Fed is certainly sufficiently important-should be able both to make monetary policy and to be reevaluating its policies and its policy framework as a regular part of its daily work. The extent of the changes that it wants to make at any moment, and the question of when to make them, are matters of its internal organization and its capacity for taking action.

A major central bank or a well-organized smaller central bank should be able to change its policy framework rapidly. And if it cannot, it should come up with a plan for making changes on the fastest possible schedule, if that is essential to the situation in which it finds itself. A change that could be made immediately if there had been enough time to plan it can be made on a slower, more gradual schedule if that is the best that can be done at a 
moment in time. ${ }^{1}$ Further, a well-run central bank should have made plans to deal with emergency situations, and carried out dry runs or table-top exercises of those plans.

Fuhrer and his colleagues discuss the Federal Open Market Committee's (FOMC's) "Statement on Longer-Run Goals and Monetary Policy Strategy," which has been published each January since 2012. As vice chair of the Fed, I was chairman of the FOMC's Subcommittee on Communications, and thus was responsible-together with the subcommittee members, Loretta Mester, Jerome Powell, and John Williams-for advising on revisions to be presented to the FOMC for the annual "Statement on Longer-Run Goals and Monetary Policy Strategy."

It was not easy going. The subcommittee's main goal during that period was to make the meaning of the statement on the symmetry of the inflation target clearer than it had been. After considerable discussion, the FOMC inserted the following words, namely, that it "would be concerned if inflation were running persistently above or below this objective." 2 This sounds trivial; but so far as I remember, no one regarded the discussion as illogical, and each variant on the statement had its own advantages and difficulties.

Although the statement has been evaluated regularly, if only for a few years, Fuhrer and his colleagues imply that they do not believe that the statement meets the definition of a Monetary Policy Framework (MPF). They are right.

Why? Because the authors' definition of an MPF "Statement on LongerRun Goals and Monetary Policy Strategy" is appropriately much broader than the material presented in the Fed's annual statement. Their definition is that such an MPF statement comprises "the set of tools and processes by which the central bank attempts to define and attain its high-level economic goals"- and that is much more than is contained in the statement.

Fuhrer and his colleagues provide a definition of an MPF that includes:

- The governance structure of the central bank.

-A set of ultimate goals for the central bank.

-A loss function.

- The instruments that the central bank directly controls in order to achieve its key goals.

1. These comments are also probably relevant to institutions other than central banks.

2. The "this" in this statement refers to the inflation target. Federal Open Market Committee, "Statement on Longer-Run Goals and Monetary Policy Strategy, Adopted Effective January 24, 2012; as Amended Effective January 26, 2016, https://www.federalreserve.gov/ monetarypolicy/files/FOMC_LongerRunGoals_20160126.pdf. 
- Transparency, including the predictability of monetary policy and "managing expectations" and forward guidance. The transparency category is very broad, and its empirical implementation is difficult to summarize. But the concept-perhaps under another name-is clearly extremely important.

- Rules and discretion: the systematic component of monetary policy As Fuhrer and his colleagues argue, "To the extent that a central bank's behavior can be well described by a policy rule, ... policy predictability will be enhanced, and the transmission channel will be more effective." "Discretion" is included because "truly optimal policy may deviate noticeably from simple rules under certain conditions."

- The central bank's depiction of the economy, that is, the model, "broadly speaking."

By this point, the definition of the MPF has become blurred. Is the model the MPF? Clearly not; for the goals of policy-the governance of the central bank, and particularly its policy process-are parts of the MPF. But does a shift from an assumption about the consumption function, or expectations generation, imply a change in the MPF? That is not clear.

Presumably, if we follow the approach of Fuhrer and his colleagues, we need to use the word "significant" somewhere-for example, by stating that the MPF changes when a revision implies significant changes in monetary policy for a given state of the economy. Clearly, the word "significant" is a weasel word, which would allow many an argument about whether the MPF will be or has been changed by a specific change or set of changes in the actions of the central bank in a given state of the economy.

And this raises the question of whether we need the concept of "evaluation" of the MPF. Decisionmakers and researchers should be evaluating what the central bank is doing whenever they are making decisions on its behalf. Someone who wants to change some aspects of an organization's behavior should have to discuss their recommendation with colleagues and managers, who should evaluate the proposed change and decide whether to implement it. What will be evaluated is a suggestion for changing one or more of the ways in which the firm or institution carries out its tasks. ${ }^{3}$

Fuhrer and his colleagues cite a 2004 paper by Alan Greenspan that discusses the centrality of risk management to monetary policy decisions. But

3. Fuhrer and his colleagues also note, later in the paper, "As Fed insiders, we wish to emphasize that the framework is to some extent always under discussion and debate." 
they conclude that it is beyond the scope of their paper to provide a precise analytical framework for the Fed's response to risks. I will return to this issue toward the end of my comment.

A REVIEW OF MPFs SINCE THE 1960s Consistent with the conventional view, the authors identify the breakdown of the post-World War II MPF as having occurred in the middle to late 1960s. They add that the next major regime began with the appointment of Chairman Arthur Burns, and they identify this regime as continuing the upward trend in inflation that began in the second half of the 1960s.

Continuing the chronology, they talk about the inflation of the 1970s, which they characterize as changing views about inflation dynamics that resulted in the inflation process appearing to have become accelerationista change that they attribute to Milton Friedman's presidential address to the American Economic Association. In light of oil price increases, they mention cost-push inflation and Chairman Burns's 1970 view that costpush inflation could not be dealt with successfully from the monetary side, and that it would be a great mistake to try doing so. They point out, in addition, that estimates of longer-run inflation increased steadily over the course of the 1970s_-but that long-run responses to inflation and unemployment have been relatively stable over time.

They note that the emphasis on output stabilization and the sacrifice ratio "raises the much-discussed issue of Fed independence" from the political cycle. They mention favorably the Humphrey-Hawkins Act of 1978, which provided the basis for the FOMC's dual (perhaps triple) mandate of "maximum employment, stable prices, and moderate long-term interest rates."

Then the good news: "The target-less regime began to crumble by the end of the 1970s." This crumbling was brought about by the appointment of Paul Volcker as chairman of the Fed. The authors say that primitive discussions about Fed independence, which were often couched in terms of "credibility," then began. If the discussions of Fed independence at that time were primitive, that was partly because the discussion in the United States did not take into account some of the foreign literature-including, for example, the works of Richard Sayers, who was the historian of the Bank of England and a professor at the London School of Economics and Political Science. ${ }^{4}$

4. See, for instance, Richard Sidney Sayers, The Bank of England 1891-1944, Volume 1 (Cambridge: Cambridge University Press Archive, 1976). 
The authors' summary of the period through the end of the Volcker era states that "it seems reasonably clear that the monetary policy framework has changed along several important dimensions since the late 1960s." And so it has.

THE PROCESS OF REGULARLY EVALUATING THE FRAMEWORK Fuhrer and his colleagues are enthusiastic about the possibility of regularly evaluating the framework. They are impressed, as I have been in the past, by the Canadian law requiring the chair of the central bank and the finance minister to reach a new agreement on the goals of monetary policy every 5 years. I have heard rumors that some Canadian monetary policymakers are now contemplating turning the 5 years into 10 years.

The authors mention 12 elements that will need to be dealt with in putting a regular evaluation of monetary policy in place. Some of these elements give cause for concern. Let me focus first on two of them.

First: "Would a more open and regular evaluation of the monetary policy framework improve policy in the United States?" In this regard:

- One of the most important changes in the behavior of the economy in recent years in the U.S. and in other countries is that there is now considerable global agreement on the inflation target, namely, 2 percent. This is a significant achievement, for it means that there is now close to a consensus about the long-term value of money in the United States and Canada, the euro zone, and in Australasia-something that did not exist at all under the gold standard, or in the days of the effectiveness of the Bretton Woods framework.

- The assessment should not be tied to the term of the chair, for the Fed is not a political body with the holder of the chair as its leader; rather, we should see the Fed as making rules and implementing monetary policy as a technical matter of what is good for the economy, preferably for the long run.

- For essentially the same reason, mutatis mutandis, the term of the regular evaluations should have nothing to do with the federal political cycle.

- In brief, we would be worsening, not improving, monetary policy if we tied its execution to a single individual, or to the political cycle.

Second: "The consideration of a specific change in the lead-up to a formal evaluation, if it became public, could similarly increase uncertainty about the Fed's actions in coming years." Canadian policymakers with whom I have spoken do not seem to worry about this potential problem. I do. But we should also note that the Canadians have undertaken an evaluation of the potential need for changes in the MPF six times, and did not change the target inflation rate after the first evaluation. 
Two more of the 12 questions asked by Fuhrer and his colleagues are also important.

First: Could a more formal, and open, review process improve how well [the Fed] adhere[s] to [its] current framework? Could transitions to a new framework be made more effectively? A central bank not burdened by the need to invoke meetings of the large number of people that would be involved in the kind of framework for an evaluation that the authors seem to be considering, could move much more rapidly in changing whatever features of the MPF are deemed necessary to change.

And second, in this section, the authors ask on whose inputs the Fed should draw. They present an impressive list of candidates, namely:

- other central banks;

- academics whose research focuses on central bank issues;

- participants in financial markets, who are part of the transmission mechanism of Fed actions to other markets;

- other policy institutions and think tanks that focus on central banking issues;

- representatives of the federal government; and

- members of the financial press.

Fuhrer and his colleagues present a quite long discussion of whether to include representatives of the federal government among those whose opinions should be consulted. This is a delicate issue, for representatives of the federal government would probably ask whether they should not be the first consultees, rather than any of the four groups above them in the list - that is, other central banks, academics, financial market participants, and other policy institutions and think tanks. Any process for evaluating revisions of the operation of the central bank will need to wrestle with the fact that "independence" for the central bank has a considerable element of independence from the political system in its meaning. Also, the authors' discussion is not sufficiently sensitive to this difficulty, which could mean that an attempt to improve the MPF would instead contribute to politicizing the revision process.

In this regard, it is important that we take into account the difference between (1) parliamentary political systems, in which the government typically has an effective majority in the parliament, and in which the central bank can make agreements with the government by discussions with only a few political policymakers; and (2) the congressional system, in which an agreement on changing the monetary policy framework could well require reaching an agreement with many political policymakers. Anyone thinking about this process could come to understand the difference between 
operating in a parliamentary system like that of Britain and in countries whose political systems are more similar to the American congressional system by comparing the process by which the Bank of England was made independent in 1997-98 with the creation of the third U.S. central bankthe Federal Reserve- that is described in Roger Lowenstein's book America's Bank (2015), which details the political maneuvering that led to the creation of the Fed in 1913.

IS NOW A TIME TO RETHINK MPFs? This penultimate section examines three issues that suggest to Fuhrer and his colleagues that we should be rethinking the monetary policy regime. The first issue is the effective lower bound on the interest rate. This problem has been analyzed in depth, and there has been some progress in dealing with it, including the possibilities of negative interest rates and of quantitative easing. Neither of these possibilities fills policymakers or the average citizen with joy, but they do suggest ways of responding to an interest rate that goes negative or threatens to do so.

The second issue is that of the chronic overshooting of the unemployment target in most of the recoveries in the U.S. economy since 1949. Fuhrer and his colleagues suggest that we have never seen an "undershoot," in which the unemployment rate plateaus above the estimated natural rate before the economy slips into a recession. In this context, one might want to think of the supply-side recessions of the 1970s and 1980s as examples of an undershoot of this type. ${ }^{5}$ Nonetheless, more prominently, there has been a repeated and chronic overshooting of the unemployment rate target, in which the policymakers have in each cycle since 1949 "shown a pronounced tendency" to drive the unemployment rate below their estimates of the natural rate at the end of the cycle, as is the case at this momentexcept that we do not know yet when this cycle will end. Further, they note that in every case the overshooting has been followed by a recession.

Having voted for a path that undershoots the target unemployment rate in the current cycle, I believe the tendency arises from the fact that although our utility function is quadratic around a higher unemployment rate than the present one, we continue to believe that less unemployment with inflation very close to the inflation target is a good place to be. Or, in other words, the main reason for our arguing that the natural rate of unemployment is higher than the current rate of unemployment is our fear of the inflation that is likely to follow if we push the unemployment

5. In the discussion here, the words "undershoot" and "overshoot" sometimes change their meanings for the direction of monetary policy changes. 
rate down too far, rather than our studies of the greater efficiency of the labor markets at a higher unemployment rate than the current one.

The third instance is our increasing reliance on unobservable or estimated variables. At Jackson Hole, we heard from Chair Powell of the exploding stars $-r^{*}, u^{*}$, and $p i^{*}$ (Powell 2018). It is indeed a problem that we need to estimate these variables, but there is a firm analytic definition of each of these stars that makes them worth studying.

In discussing the alternatives to our current procedures, Fuhrer and his colleagues mention the possibility of operating with an inflation target range rather than a point target. This is what is contained in the revised Bank of Israel law, passed in 2010. The inflation target in Israel is 2 percent, with a target range of 1 to 3 percent. This approach works, and in my opinion the United States would be better off adopting a target range than a single number-but that will not solve the problem of the zero lower bound. Rather, it was included in the Israeli law to solve the problem of an economy with a large trade sector where movements in the exchange rate have frequent, large, and rapid effects on the inflation rate.

At the end, Fuhrer and his colleagues suggest that one-or perhaps many - should consider whether there could be an important role in stabilization policy for fiscal policy. Having raised the question, they move on rapidly by stating that that is a topic for another paper, and, they implicitly add, for another day. But it is clear that dealing better with crises will require better coordination between monetary and fiscal policy than has been typical in the United States.

CONCLUSION I would like to conclude these remarks by noting the importance of two topics that will require more discussion than they have received in the already-far-reaching paper by Fuhrer and his colleagues. The first is the treatment of risks and uncertainty in the policy process. We need to better prepare the U.S. monetary system for unexpected events than was evident in 2008 and 2009. I speak with the understanding that we will not be able to prepare precisely for future crises, for each crisis is somewhat different-and, as was noted in the discussion of Ben Bernanke's paper (2018), developments in each crisis will depend also on changes in the approaches to each crisis by monetary policymakers. But what policymakers in institutions for whom fighting crises is an important part of their mission certainly realize is that preparations made in exercises to deal with future crises themselves generate improvements in the institutions' capacity to contend with crises. To put it clearly, there is typically no manual that a central bank can simply pull off the shelf to deal effectively with a crisis—but thinking about and carrying 
out desk exercises for dealing with a crisis will reveal changes that need to be made to improve the management of future crises.

Second, it is clear that problems in bank supervision and regulation played an important role in the processes that led up to the Great Financial Crisis. We do not yet have an efficient system for coordinating the responses of different agencies for dealing with future financial crises. And it may well take another round of reform in the supervisory/regulatory system to improve the treatment of the problems that are now visible in this system, including questions about the operation of the lender of last resort.

In summary, Fuhrer and his colleagues have written an ambitious and interesting paper, with a high level of productivity, even on a per author basis. However, the paper does not make a persuasive case for monetary policy reforms to be undertaken on a fixed schedule, rather than continuously, as the profession and the central bank make progress in their research, and as the world throws up new challenges and facts that will require changes in current and future economic policies. This paper will likely be seen as an important early contributor to that discussion as it progresses.

\section{REFERENCES FOR THE FISCHER COMMENT}

Bernanke, Ben S. 2018. "The Real Effects of Disrupted Credit: Evidence from the Global Financial Crisis." In this issue of Brookings Papers on Economic Activity.

Lowenstein, Roger. 2015. America's Bank: The Epic Struggle to Create the Federal Reserve. New York: Penguin Press.

Powell, Jerome H. 2018. Monetary Policy in a Changing Economy. Speech given at "Changing Market Structure and Implications for Monetary Policy," symposium sponsored by Federal Reserve Bank of Kansas City, Jackson Hole, Wyo., August 24. https://www.federalreserve.gov/newsevents/speech/powell20180824a.htm.

GENERAL DISCUSSION Alan Blinder remarked that in some cases, institutional inertia at the Federal Reserve can be an advantage rather than a hindrance. For example, both the Supreme Court and the Federal Reserve are less subject to politics and, as a consequence, are less subject to the more volatile policy whims of Congress. Blinder also remarked that the continuous optimization of policy taught in economics courses should probably not apply to the Fed. Regarding politics, Blinder remarked that there are clear differences between changes in the Fed's framework and changes that would actually require alterations to the Federal Reserve Act. 
For example, changes to the dual mandate would require a revision of the law by Congress. However, changing the inflation target or estimates of the neutral rate of interest would not require any change in the law, but are nonetheless very important to policy. For example, revisions to estimates of the neutral rate of about 1 percentage point would dramatically change monetary policy. Blinder argued that changes at the Fed that require legislation should be very rare, and only occur when the Fed is consistently failing to meet its mandate. Changes to the Fed's framework that do not require Congress's approval should be done continuously rather than as some discrete event that invites political participation.

Alice Rivlin agreed with Blinder that the Federal Reserve should constantly be revising its policy framework; she believes it currently operates as such. In fact, she noted that the Fed's focus on monetary policy is proportionally greater than its focus on other policies, in part because the Federal Open Market Committee (FOMC) is a receptive audience. The framework for fiscal policy does not generate the same degree of attention because there is no equivalent audience. She noted that one of the dangers of formalizing a process around the Fed's framework is to overemphasize monetary policy and deemphasize things like fiscal policy that deserve more attention.

Frederic Mishkin noted his conflicting views vis-à-vis a formal review of the monetary framework. On the affirmative side, he referenced the successful push for adopting inflation targeting as part of the Fed's framework and its emphasis on the role of institutions. Good institutional governance and less reliance on individuals was a crucial argument for the inflationtargeting framework. He noted that there were several episodes in which the Fed did not formally consider its framework and instead relied on individuals, which led to major policy mistakes. For example, he noted the policies of former Fed chair Arthur Burns. The Burns Fed overemphasized employment as part of its mandate, and as a result facilitated the Great Inflation of the 1970s. The lesson of these policies, Mishkin argued, is to not have overconfidence about the natural rate of unemployment but to instead focus on inflation and what it might tell policymakers about the natural rate of unemployment. A second example was then-Fed chairman Alan Greenspan's opposition to institutional transparency at the Fed. Mishkin described a past FOMC meeting at which inflation targeting was discussed. Then-San Francisco Fed president Robert Parry, who was considered more conservative, and then-Fed vice chair Janet Yellen, who was considered more liberal, agreed on the need for an inflation target. However, Chair Greenspan shut down the conversation and forcefully opposed an explicit 
2 percent inflation target. Both these examples illustrate why a formal review process could improve governance and policy at the Fed.

However, Mishkin also agreed with commenters Stanley Fischer and Jean Boivin about the importance of political economy. Though a formal review process involving outside actors might improve the Fed's democratic accountability, there are some questions about how such a process would be implemented. For example, Mishkin cited congressional proposals to "audit the Fed." These proposals, he argued, are really about ending the Fed entirely, because they would allow Congress to counteract specific interest rate decisions by the central bank, hindering its independence. Former senator Ron Paul, one of this policy's main proponents, has explicitly written that he wants to end the Fed. Such a proposal shows the risks of a potential "audit" of the Fed's framework. Mishkin noted that certain countries with parliamentary systems, such as Sweden, have successfully used such a process by focusing on the framework rather than the central bank's day-to-day decisions. Mishkin observed that other countries that have implemented a successful review of the framework, such as Canada, have made the process more technocratic. These countries have avoided "big picture" issues and therefore sidestepped politics. He pointed out that a regular review process, conducted perhaps every three years, would make sense, but that implementing it effectively without criticizing current policy or interfering with the Fed's independence would require subtlety and a focus on the details.

Philipp Hartmann praised the authors for their paper and overall contributions to important debates over the years on central banks. Although the European Central Bank (ECB) is currently not conducting a review of its monetary policy strategy, he thought he would bring some of the euro area practices into the debate, so participants could make comparisons with the United States. First, he noted that the ECB undertakes regular and relatively frequent internal reviews of specific monetary policy instruments, programs, or frameworks. Second, he noted a major review of the ECB's monetary policy strategy in 2003, which is described in detail in the Hartmann and Smets paper presented earlier at the panel. This review led to important clarifications and changes with respect to the ECB's quantitative definition of price stability, the role of the "monetary pillar" in its strategy, and the structure of the ECB president's introductory statement at monetary policy press conferences. Ex ante, these two types of reviews do not actively involve parties outside the Eurosystem, except when a consultant is hired from academia or another central bank. Nevertheless, apart from undertaking its own analyses, the ECB collects large volumes of materials from academia and takes the views of outside 
commentators and stakeholders into account. Ex post, the results of such reviews may then be publicly announced.

In what concerns the possibility of actively involving non-central bank stakeholders or the general public in reviews of the ECB's monetary policy framework, Hartmann referred to specificities in Europe compared with mature countries with federal systems, such as the United States. First, it would be very complicated to involve stakeholder groups from the 19 different euro area countries. Moreover, it is very challenging to communicate on such complicated matters with the public and the media of all these countries. The existence of different languages, policy cultures, and traditions often leads to the same message being interpreted differently across the euro area countries.

Regarding the metrics to be used in such a review of the monetary policy framework, Hartmann noted that a standard central bank loss function, as widely used in the academic literature and also in the paper by Fuhrer and his colleagues, could not be a primary one for the ECB's case. This is due to the ECB's single mandate with a primary objective of price stability, which allows it to pursue other objectives such as full employment only in lexicographic order. ${ }^{1}$ Hartmann discussed the issue with the Harvard University economist Benjamin Friedman, but ultimately felt that the ECB could use such loss functions at best as a secondary input. Hartmann also noted that for central banks in general, it now seems particularly important to discuss the role of financial stability in their monetary policy frameworks. For a review involving outside stakeholders, however, this might significantly enlarge the number of parties.

Finally, Hartmann referred to an effect of a public review that had not yet been mentioned in the discussion (but perhaps hinted at by the last remark of Frederic Mishkin). The fact that aspects of the existing monetary policy framework are being questioned could have implications for the transmission of current policy and, ultimately, policy effectiveness. This transitional risk would need to be actively managed through communication until all uncertainties are resolved again, probably without being able to entirely exclude the possibility of unintended adverse effects.

Olivier Blanchard recommended the International Monetary Fund's internal review process as a potentially useful model. This process is conducted internally but by independent reviewers, it relies on academics, and

1. A similar point is made by John Driffill and Zeno Rotondi, "Monetary Policy and Lexicographic Preference Ordering," CEPR Discussion Paper 4247 (Washington: Center for Economic Policy Research, 2004). 
it focuses on specific aspects of the IMF's framework rather than on the overall mandate. Blanchard suggested that this process works reasonably well and sidesteps political controversy.

Eric Rosengren responded to the commenters and other discussants by noting that their paper was not focused on changes to the monetary policy framework that would involve changes to the Federal Reserve Act. Many changes in the framework had occurred in the past without changes to this law, and these types of changes were their focus in the paper. Rosengren noted that the framework can be broader than just focusing on goals. For example, the statement on longer-run goals and policy strategy released by the Fed every January highlights the loss function, operating instruments, and transparency. He also emphasized that changing the framework without involving outside parties or being transparent does not eliminate the political economy problems raised by the commenters and discussants. He therefore argued that public discussion does have some merit as part of a review process. For example, many of the Fed's transparency initiatives, including those highlighted by Frederic Mishkin, were considered inconceivable in the past. In fact, the Fed would have been better off if it had moved earlier toward greater transparency. How the review process itself should be structured would be up for debate, but making it regular and structured to ensure that changes to the framework do indeed occur seems like the vital point.

Jeff Fuhrer noted that the convening process that would be a part of the review of the monetary policy framework that he and his colleagues propose in their paper is not supposed to definitively set the Fed's framework. Instead, it is supposed to be used to obtain input as the FOMC considers alternatives. The Fed would be responsible for determining the agenda and inviting attendees, and it could be selective in doing so. The paper also does not argue for having the process occur around elections, and the authors do not believe the review process should be politicized. Finally, Fuhrer noted that the review process conducted by the Bank of Canada could not be directly transplanted and used in the United States, due to the different relationship between the government and the central bank in the two countries. In Canada, the government is more directly involved in the process. The authors suggest in their paper that the process should include input from government experts, while being careful to maintain the Fed's independence in deciding on its framework's technical aspects. 